Article

\title{
Improvement of SCS-CN Initial Abstraction Coefficient in the Czech Republic: A Study of Five Catchments
}

\author{
Martin Caletka 1,2,*, Monika Šulc Michalková ${ }^{2}$, Petr Karásek ${ }^{3}$ and Petr Fučík $^{3}$ (D) \\ 1 T. G. Masaryk Water Research Institute, Podbabská 30, 16000 Praha, Czech Republic \\ 2 Department of Geography, Faculty of Science, Masaryk University, Kotlářská 2, 61137 Brno, \\ Czech Republic; sulc@mail.muni.cz \\ 3 Research Institute for Soil and Water Conservation, Žabovřeská 250, 15627 Praha, Czech Republic; \\ karasek.petr@vumop.cz (P.K.); fucik.petr@vumop.cz (P.F.) \\ * Correspondence: 323980@mail.muni.cz; Tel.: +420-737-651-313
}

Received: 19 May 2020; Accepted: 3 July 2020; Published: 10 July 2020

check for updates

\begin{abstract}
The SCS-CN method is a globally known procedure used primarily for direct-runoff estimates. It also is integrated in many modelling applications. However, the method was developed in specific geographical conditions, often making its universal applicability problematic. This study aims to determine appropriate values of initial abstraction coefficients $\lambda$ and curve numbers (CNs), based on measured data in five experimental catchments in the Czech Republic, well representing the physiographic conditions in Central Europe, to improve direct-runoff estimates. Captured rainfall-runoff events were split into calibration and validation datasets. The calibration dataset was analysed by applying three approaches: (1) Modifying $\lambda$, both discrete and interpolated, using the tabulated $C N$ values; (2) event analysis based on accumulated rainfall depth at the moment runoff starts to form; and (3) model fitting, an iterative procedure, to search for a pair of $\lambda, S$ ( $C N$, respectively). To assess individual rainfall characteristics' possible influence, a principal component analysis and cluster analysis were conducted. The results indicate that the $\mathrm{CN}$ method in its traditional arrangement is not very applicable in the five experimental catchments and demands corresponding modifications to determine $\lambda$ and $C N$ (or $S$, respectively). Both $\lambda$ and $C N$ should be viewed as flexible, catchment-dependent (regional) parameters, rather than fixed values. The acquired findings show the need for a systematic yet site-specific revision of the traditional $\mathrm{CN}$ method, which may help to improve the accuracy of $\mathrm{CN}$-based rainfall-runoff modelling.
\end{abstract}

Keywords: curve number; direct runoff; HEC-HMS; initial abstraction coefficient; rainfall-runoff modelling; SCS-CN

\section{Introduction}

The Soil Conservation Service Curve Number (SCS-CN) method is an empirical lumped rainfall-runoff model developed in 1954 by the US Department of Agriculture's Soil Conservation Service (USDA SCS, now the Natural Resources Conservation Service NRCS). Originally, the method entailed converting basic descriptive inputs characterising catchment features into numeric values of curve numbers (CNs) [1]. For any given rainfall amount, the corresponding runoff level is estimated. The procedure is based on a combination of the water-balance equation 


$$
P=I a+F+Q,
$$

and two fundamental assumptions,

$$
\begin{gathered}
\frac{Q}{P-I a}=\frac{F}{S}, \\
I a=\lambda S
\end{gathered}
$$

in which $Q$ is direct runoff $(\mathrm{mm}) ; P$ is precipitation $(\mathrm{mm}) ; I a$ is initial abstraction $(\mathrm{mm})$ that has to be exceeded so that direct runoff can start to form; $F$ is cumulative infiltration $(\mathrm{mm})$, not including $I a$; $S$ is maximum potential retention of a watershed after the start of the runoff and $\lambda$ is initial abstraction ratio (dimensionless).

The runoff depth $Q$ is expressed using Equations (1)-(3) as

$$
Q=\frac{(P-\lambda S)^{2}}{(P+(1-\lambda) S} \text { for } P>I a, Q=0 \text { for } P \leq I a \text {. }
$$

The maximum potential retention $S$ is expressed as a function

$$
S=\frac{25400}{C N}-254,
$$

in which $C N$ is the curve number, theoretically ranging between 0 and 100 . Over the years, the method has undergone numerous modifications [2-6], during which time the scientific community adopted the method globally for its simplicity, applicability and relatively low demands on input data [7-11].

The $C N$ method has various shortcomings regarding practical applications in different geographical conditions. For example, the initial abstraction coefficient $\lambda$ 's validity has been questioned [11-14]. Similarly, the role of a watershed's relief and land cover [15-20], previous rainfall's influence [19-21] and $C N$ values' representativeness $[16,22,23]$ in terms of properly setting the method have been scrutinised.

Attention has been payed to the ability of a single $C N$ value to characterise the runoff response of a watershed correctly. While the $C N$ may be calculated from observed $P-Q$ data, practical experience shows that the $C N$ values vary between events $[11,24]$. Therefore, various approaches were introduced aiming to estimate an appropriate single $C N$ value or single asymptotic $C N$, separately [1,25-29]. However, the aforementioned methods showed certain shortcomings addressed by a study that analysed the effect of soil and land cover complexes on the hydrologic responses in watersheds [30]. Specifically, the authors proposed a concept of a two-CN heterogenous system. This study was subsequently generalised [31]. The latter two methods along with other $C N$ estimation methods were used and compared in a study [32] of a watershed affected by a major forest fire, so that the effect of both spatial heterogeneity in land cover and the fire could be investigated.

Another problematic aspect of the $\mathrm{CN}$ method lies in the characterisation of previous rainfall. It is expressed using three antecedent moisture condition (AMC) classes (I: Dry; II: Normal; and III: Wet), each of which has its own set of CNs. The discrete character of the $C N$-AMC relationship is manifested by sudden jumps in estimated runoff [33]. On the basis of previous five-day rainfall totals, $C N_{I I}$ is converted to $C N_{I}$ and $C N_{I I I}$ using relationships proposed by [24-37] and directly from the NEH-4 tables $[4,38,39]$. Despite the existence of different conversion methods, the discontinuity problem remained unresolved, and the concept of soil moisture accounting (SMA) became a subject of research. Williams and LaSeur [40] presented the first SMA concept. Their procedure was based on the idea that the $C N$ varies continuously, along with soil moisture. Hawkins [41] then developed a continuous soil moisture accounting concept, but this modification did not take into account the SCS-CN procedure's structural shortcomings in terms of SMA, a problem addressed by Mishra et al. [42], who introduced an improved SMA-based SCS-CN model. Subsequently, Mishra and Singh [43] developed a versatile SCS-CN model (VSCS-CN) based on the assumption that higher antecedent soil moisture before a rainfall event will provide greater runoff and lower the soil's capacity to store and retain rainfall water. 
Similarly, Michel et al. [44] also examined such a concept. Mishra and Singh [21] used a concept that comprised a runoff coefficient and the degree of saturation on the basis of which multiple improved SCS-CN models have been proposed [19,45-49].

Relief is a significant factor in runoff formation [50,51], but slope was not reflected in the traditional $\mathrm{CN}$ model. The NRCS handbook's CN values [6] are viewed as corresponding to a 5\% slope $[18,20,51,52]$. However, some approaches exist that incorporate slope into the CN estimates. For example, Huang et al. [51] modified the procedure by Sharpley and Williams [18] for steep watersheds in Loess Plateau, China. Their method then was adjusted for rainfall-runoff data from 39 South Korean watersheds. However, according to Mishra et al. [8], the aforementioned procedures require proper validation.

Inaccuracies in direct-runoff modelling are frequently associated with the initial abstraction Ia or $\lambda$, separately. Ia was not incorporated into the original CN method [52]. During its evolution, a constant value of 0.2 was set for $\lambda[4,53]$, but many authors challenged this. Trying to identify this constant's appropriate value has been a matter of many debates and studies conducted to estimate the appropriate value of $\lambda$. It was concluded by several studies that $\lambda$ values result from multiple factors related to rainfall events and landscape features $[22,54,55]$ and that the coefficient should be viewed as a regional parameter expressing geographical variability [10]. Some researchers concluded stated that $\lambda$ can take any non-negative value, in some cases even greater than 1 [55-59]. However, many authors stated that using reduced $\lambda$ led to much more accurate results, e.g., [2,11-13,60-64].

In the Czech Republic, the $\mathrm{CN}$ method is applied frequently, using tabulated $\mathrm{CN}$ values [65]. The value of $\lambda$ implicitly is set at 0.2 , but such a value does not appear to be representative, as preliminary studies by Caletka and Honek [66] and Caletka and Michalková [67] concluded. The CN method is the subject of greater interest in Slovakia where several studies were conducted in recent years. Karabová [68] analysed rainfall-runoff data from five lowland watersheds in Slovakia, addressing the problem of regionalisation of runoff curve through a new AMC classification and application of $\lambda-P$ regressions. The study concluded that the traditional $\mathrm{CN}$ method lead to over-estimated direct runoff for lower $P$ and vice versa. Similarly, Kohnová et al. [69] analysed rainfall-runoff data from nine watersheds in central Slovakia and concluded that the standard CN method demanded certain modifications. Specifically, they stated that $C N$ s should be estimated on the basis of observed rainfall-runoff data, rather than using tabulated values. Moreover, they used the variable $\lambda$ value instead of the fixed one. Another study [23] compared the original CN method's performance with that based on empirical rainfall-runoff events using different approaches. They stated that the $\mathrm{CN}$ method was burdened by a lot of uncertainty. Using asymptotic fitting procedure of median procedure with reduced $\lambda=0.05$ increased the accuracy of the results. Recently, Kohnová et al. [70] proposed and evaluated the performance of a regionally based approach to estimate $C N$ along with different $\lambda$ values. They collected data in a group of Slovak and Polish catchments and used the $L$-moment based method and ANOVA for delineation of two homogenous regions of catchments with similar CNs. The optimal value of $\lambda$ was set to 0.15 .

Given that the application of the $\mathrm{CN}$ method in its original form is problematic, based on findings in many studies, this research focuses on an analysis of recorded rainfall-runoff data from five experimental watersheds in the Czech Republic with various geomorphological and agricultural conditions. This study's main objectives are: (1) To calculate adjusted $\lambda$ both as discrete values and regression functions; (2) to compare the $\mathrm{CN}$ method's performance using adjusted $\lambda$ values; and (3) to test the application of the modified CN method in HEC-HMS simulations of specific rainfall-runoff events in a chosen catchment. 


\section{Study Area}

The study was carried out in five experimental watersheds in the Czech Republic (Figure 1), differing mainly in size and in land use. This made it possible to assess the CN method's performance and interpret the findings of this research with regard to each watershed's specific geographical conditions. All the studied watersheds' basic characteristics are provided in Table 1.

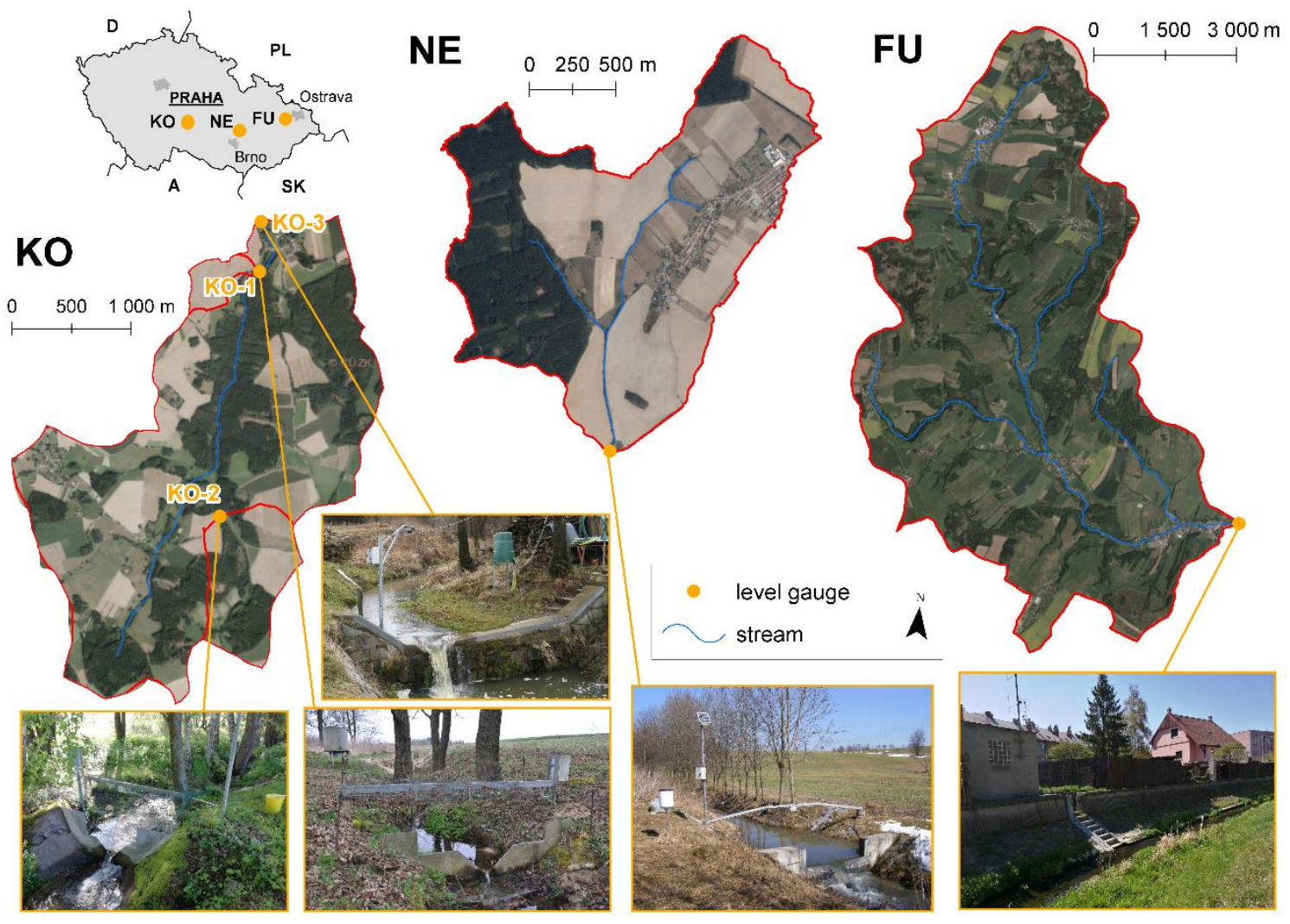

Figure 1. Overview map of the experimental catchments.

Table 1. Basic characteristics of the experimental catchments and percentage of land use categories (AL—arable land; BG—-bare ground; FO—forest; GR—grassland and meadows; GA—gardens and orchards; $\mathrm{PA}$ - paved and built-up areas; $\mathrm{SH}$ - shrubbery; WA-water bodies).

\begin{tabular}{|c|c|c|c|c|c|c|c|c|c|}
\hline \multirow{2}{*}{$\begin{array}{c}\text { Sub- } \\
\text { Catchment }\end{array}$} & \multirow{2}{*}{$\begin{array}{l}\text { Area } \\
\left(\mathrm{km}^{2}\right)\end{array}$} & \multicolumn{2}{|c|}{ Elevation (m) } & \multirow{2}{*}{$\begin{array}{c}\text { Mean } \\
\text { Slope }\left({ }^{\circ}\right)\end{array}$} & \multicolumn{2}{|c|}{ Mean $P(\mathrm{~mm})$} & \multirow{2}{*}{$\begin{array}{c}\text { Mean } Q \\
\left(\mathrm{~m}^{3} / \mathrm{s}\right)\end{array}$} & \multicolumn{2}{|c|}{ Mean $T\left({ }^{\circ} \mathrm{C}\right)$} \\
\hline & & Min. & Max. & & Annual & IV-IX & & Annual & IV-IX \\
\hline FU & 57.8 & 282 & 563 & 6.1 & 675 & 450 & 0.350 & 8.0 & 13.5 \\
\hline $\mathrm{NE}$ & 2.8 & 559 & 650 & 4.2 & 650 & 400 & 0.015 & 7.0 & 14.0 \\
\hline $\mathrm{KO}-1$ & 0.16 & 490 & 532 & 3.2 & 675 & 425 & 0.007 & 6.5 & 12.5 \\
\hline $\mathrm{KO}-2$ & 0.78 & 548 & 623 & 4.3 & 675 & 425 & 0.003 & 6.5 & 12.5 \\
\hline $\mathrm{KO}-3$ & 7.1 & 478 & 623 & 5.2 & 675 & 425 & 0.026 & 6.5 & 12.5 \\
\hline \multirow{2}{*}{$\begin{array}{c}\text { Sub- } \\
\text { Catchment }\end{array}$} & \multicolumn{9}{|c|}{ Percentage of Land Use Category (\%) } \\
\hline & AL & BG & FO & GR & GA & GA & PA & SH & WA \\
\hline FU & 43.5 & 0.0 & 24.7 & 23.7 & 5.2 & 5.2 & 1.4 & 1.3 & 0.2 \\
\hline $\mathrm{NE}$ & 50.9 & 0.2 & 31.8 & 5.2 & 5.4 & 5.4 & 3.1 & 3.4 & 0.0 \\
\hline KO-1 & 97.3 & 0.0 & 0.1 & 0.0 & 1.3 & 1.3 & 0.7 & 0.6 & 0.0 \\
\hline $\mathrm{KO}-2$ & 52.2 & 0.0 & 44.4 & 1.1 & 0.6 & 0.6 & 0.1 & 1.5 & 0.0 \\
\hline $\mathrm{KO}-3$ & 41.8 & 0.0 & 37.9 & 8.0 & 6.1 & 6.1 & 0.9 & 5.2 & 0.1 \\
\hline
\end{tabular}




\subsection{Husi Creek Catchment (FU)}

Husí Creek is a left-side tributary of the Oder (Odra) River, located in northeastern Czech Republic, approximately $30 \mathrm{~km}$ southwest of the city of Ostrava. The upper parts belong to the easternmost edge of the Bohemian Massif in the Nízký Jeseník Highlands, while the lower parts lie in the Outer Subcarpathia, a depression at the outer base of the Carpathian arc. The catchment's position predetermines its specific relief; it is characterised by a flat or slightly wavy surface in the upper parts that gradually passes into narrowing valleys with greater longitudinal slope. The valleys widen downstream, and the surface becomes slightly curved to flat. Two main soil types are present in the catchment. Cambisols are found mainly in the upper parts, while luvisols are prevalent in the lower parts. As for land use, a specific spatial distribution exists. Arable land, usually in the form of large plots, is found both in the upper and lower parts of the catchment on the flat relief. Forests and meadows are located mostly in the transition between the upper and lower parts, in the valleys and along streams. This specific environment creates favourable conditions for generating flash floods from intense rainfall. Two major flash-flood events were recorded in summer 2009 and 2010 [71,72]. On 2 July 2009, the region experienced extreme rainfall (local precipitation reached up to $50 \mathrm{~mm}$ ) after a very rainy period, causing a severe flood event with peak discharge of $33.1 \mathrm{~m} / \mathrm{s}$ and corresponding to a 50-year flood event. On 1 June 2010, another rainfall event was recorded (with a maximum rain-gauge measurement of $55 \mathrm{~mm}$ ), but due to the precipitation's differing spatial distributions and lower previous rainfall, peak discharge reached only $14.4 \mathrm{~m}^{3} / \mathrm{s}$, corresponding to the return period of 5-10 years. Nevertheless, both events resulted in heavy damage to municipalities along the stream.

\subsection{Suchý Creek Catchment (NE)}

The study area is located approximately $30 \mathrm{~km}$ north of Brno in the Drahany Highlands. The catchment is drained by a minor stream, Suchý Creek, and forests cover the western part of the watershed. More than half the area is arable land. Due to large fields, soil erosion poses an imminent threat to a little dam that was constructed right under the catchment's outlet to protect the areas downstream from flash floods [73].

\subsection{Kopaninský Creek Catchment (KO)}

This catchment is located in the Křemešnice Highlands in the southern part of the Sázava River basin, a right-side tributary of the Moldau (Vltava) River. It is a source of drinking water for the City of Prague, located approximately $80 \mathrm{~km}$ to the northwest. From a geological perspective, this is a very old area formed by igneous and metamorphic rocks during the Paleozoic Era, including granite and schist. Rolling hills and low mountains dominate this region's surface, with the altitude mostly ranging between 500 and $650 \mathrm{~m}$. As for the soils, cambisols are found most frequently here, along with pseudogleys and gleys, in valleys and along streams. The landscape is covered predominantly by arable land, forests and, to a lesser extent, grasslands and meadows. The settlement is scattered in rather small villages.

The KO catchment is drained by the Kopaninský Creek. The main catchment outlet is KO-3, another two sub-catchments analysed in this study are $\mathrm{KO}-2$ and $\mathrm{KO}-1$. The $\mathrm{KO}-2$ catchment is located in the uppermost part of the KO-3 catchment and has the greatest portion of forested areas, at more than $44 \%$. The KO-1 catchment, located in the lower part, is covered almost entirely by arable land (more than 97\%) and is partly tile-drained.

All five studied watersheds' basic geographical characteristics are listed in Table 1. 


\section{Materials and Methods}

\subsection{Data Collection}

Automatic rain gauges were used to measure precipitation heights. The monitoring network included up to 17 rain gauges (automatic $0.2 \mathrm{~mm}$ tipping buckets $200 \mathrm{~cm}^{2}$ and 0.1 tipping buckets $500 \mathrm{~cm}^{2}$ ) in catchment FU and its nearby surroundings. The Thiessen polygon interpolation procedure was used to calculate average precipitation levels [74]. A single rain gauge (automatic $0.2 \mathrm{~mm}$ tipping bucket $200 \mathrm{~cm}^{2}$ ) was used to measure rainfall in catchments NE and KO. Using the precipitation data, individual rainfall events were identified, for which five- and 10-day antecedent precipitation totals $\left(P_{5 d}, P_{10 d}\right)$ were calculated.

The water level data were measured using calibrated weirs with ultrasound probes (Fiedler company) - a Thompson weir was used with in catchments NE, KO-1 and KO-2, a compound Cipolletti weir was used in catchment KO-3. In catchment FU, water levels were measured using hydrostatic level sensors (Fiedler company). Discharge values were calculated by means of rating curves set for all monitored outlets on the basis of hydrometric measurements, levelling and using the Chézy formula [75].

An overview of measuring devices is provided in Table 2.

Table 2. Overview of rainfall and level/runoff measurements in the study catchments; Number of events chosen for training and validating datasets.

\begin{tabular}{ccccc}
\hline Sub-Catchment & Period & $\begin{array}{c}\text { Number of Rain } \\
\text { Gauges (Interval) }\end{array}$ & $\begin{array}{c}\text { Level/Runoff } \\
\text { Measurement (Interval) }\end{array}$ & $\begin{array}{c}\text { Number of Events } \\
\text { Chosen } \\
\text { (Train./Valid.) }\end{array}$ \\
\hline FU & $2008-2016$ & $17(10 \mathrm{~min})$ & Level gauge $(1 \mathrm{~h})$ & $44 / 45$ \\
NE & $2008-2017$ & $1(10 \mathrm{~min})$ & Thomson weir $(10 \mathrm{~min})$ & $57 / 81$ \\
KO-1 & $2005-2018$ & $1(10 \mathrm{~min})$ & Thomson weir $(10 \mathrm{~min})$ & $56 / 52$ \\
KO-2 & $2005-2018$ & $1(10 \mathrm{~min})$ & Thomson weir $(10 \mathrm{~min})$ & $73 / 74$ \\
KO-3 & $2005-2018$ & $1(10 \mathrm{~min})$ & Cippoletti weir $(10 \mathrm{~min})$ & $80 / 60$ \\
\hline
\end{tabular}

\subsection{Estimate of $C N$ Values}

The hydrologic soil groups (HSGs) were derived based on Valuated Soil-Ecological Units (VSEUs), a whole-country database (1:5000) determined by the Research Institute for Soil and Water Conservation (RISWC). Land-cover units were identified based on aerial images and a reconnaissance field survey. The corresponding percentages are provided in Table 1, and the spatial distribution is depicted in Figure 2. Moreover, cropping and tillage history also was considered in the NE catchment. Subsequently, the final identification of CNs for each unit was done according to Janeček et al.'s [56] methodology, which frequently is applied in the Czech Republic, in which the tabulated CN values correspond to different HSGs, land-use units and crop types. Moreover, moisture conditions are reflected through antecedent moisture conditions (AMCs). AMCs are characterised by three degrees (I: Dry; II: Normal; and III: Wet), delimited by a five-day precipitation total of $P_{5 d}$ of $36 \mathrm{~mm}$ and $53 \mathrm{~mm}$ prior to a rainfall ( $P_{5 d}<36 \mathrm{~mm}$ - dry conditions; $P_{5 d} \geq 53 \mathrm{~mm}$ - wet conditions). Maps of $C N_{I I}$ values are provided in Figure 2 for each catchment. 

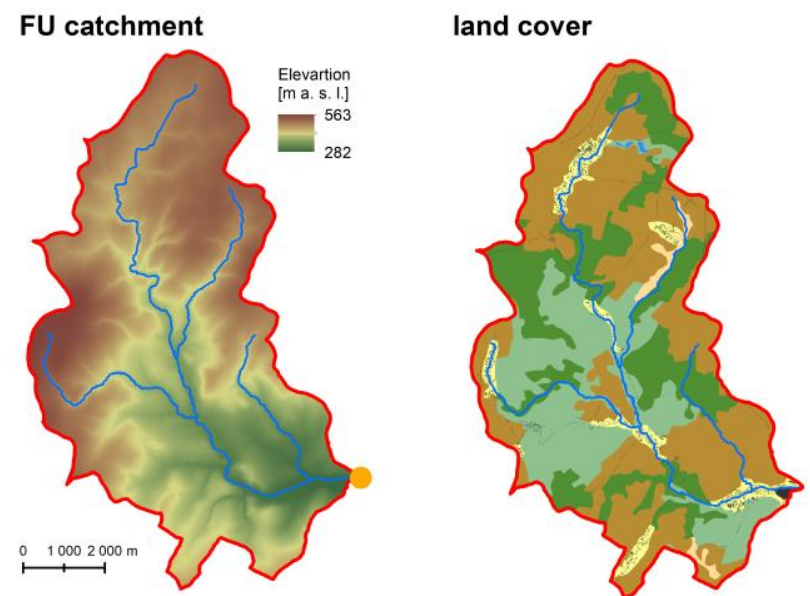

\section{CN distribution}
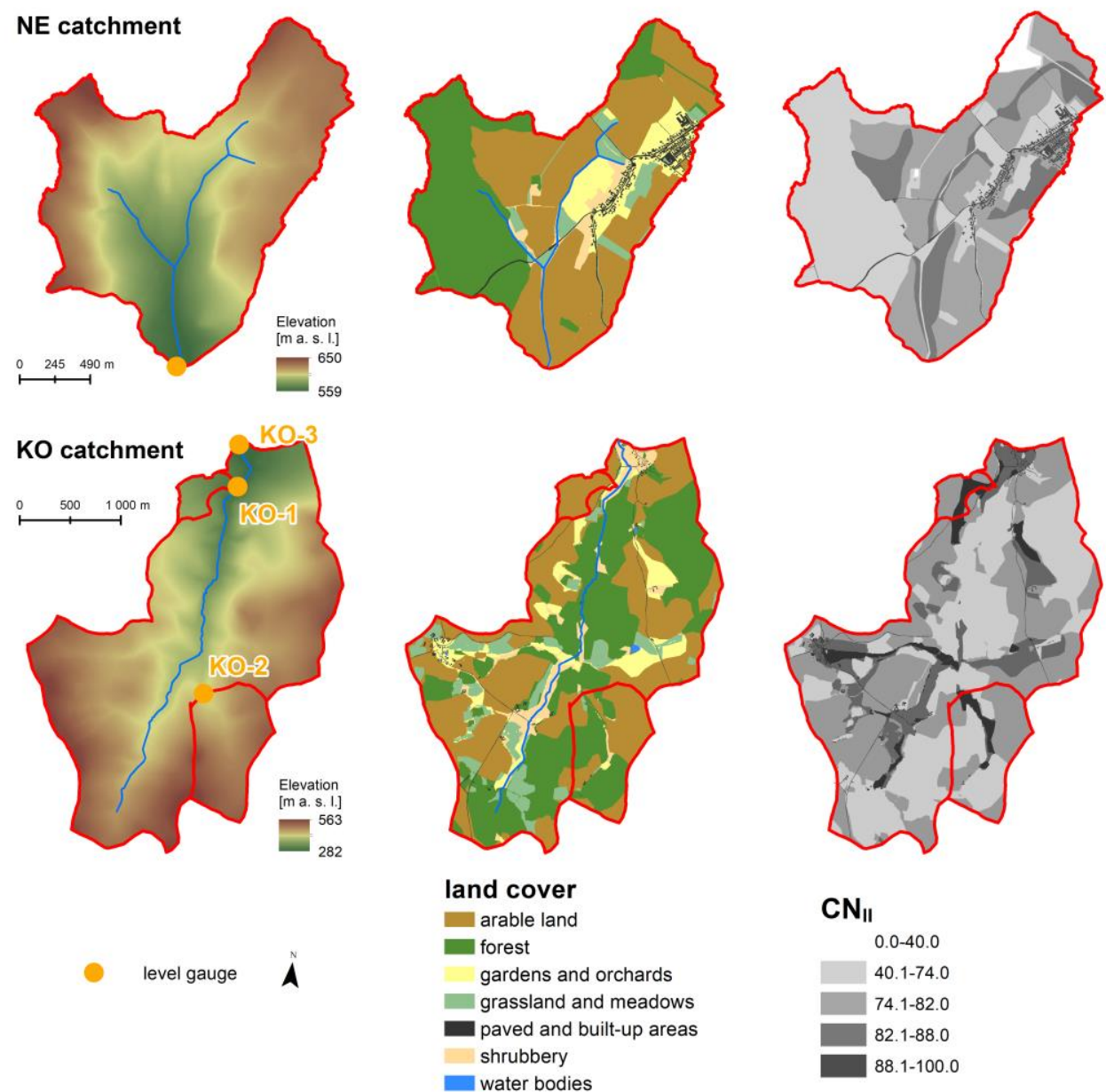

Figure 2. Surface, land cover classification and curve number $(C N)$ determination.

\subsection{Events, Determination of $\lambda$}

To avoid biased $\lambda$ values, rainfall events recorded between April and September with $P \geq 5 \mathrm{~mm}$ were chosen for the analysis. In order to exclude rainfall events that caused compound hydrographs, rainfall-runoff events were selected individually, so that the influence of runoff from previous rainfall events could be obviated. For each event, the following parameters were determined: 
1. precipitation level $P(\mathrm{~mm})$,

2. rainfall event's duration (h),

3. maximum rain intensity $i_{\max }\left(\mathrm{mm} \mathrm{h}^{-1}\right)$,

4. five- and 10-day rainfall accumulations $P_{5 d}$ and $P_{10 d}(\mathrm{~mm})$,

5. hydrograph was drawn and base flow was separated from the hydrograph based on the hydrograph's inflection points, which indicated the start of the rising limb and the end of the recession limb for each runoff event [69,70],

6. direct-runoff level $Q$ was calculated (mm),

7. initial abstraction $I a(\mathrm{~mm})$, which was calculated as the rainfall level at the moment when direct runoff begins. Such a procedure has been used for instance in research by Shi et al. [11]. However, in large watersheds and/or in case of uneven spatial distribution of precipitation such a calculation of Ia might be problematic as the runoff needs some time to reach the watershed's outlet [24].

The aforementioned parameters were applied in the analyses described in detail in the following sections. To verify the adjusted $\mathrm{CN}$ method's performance, events' datasets were split into training and validating datasets (see the numbers provided in Table 2), so that they were similar in terms of level and variability of $P, P_{5 d}$ and $P_{10 d}$.

\subsubsection{Principal Component Analysis, Cluster Analysis}

In order to reveal possible concealed relationships between parameters of rainfall-runoff events and to assess objectively the role that the individual parameters may play in the rainfall-runoff process, principal component analysis (PCA) and cluster analysis (Ward's method) were conducted for the training datasets from all experimental catchments. The cluster analysis allowed to explore groups (clusters), which the events tend to form. The optimal number of clusters was set using Pham et al.'s [76] k-selection method.

\subsubsection{Modified $\lambda$ with Tabulated CNs}

The procedure begins with the determination of tabulated $C N$ values [65] for individual units in a catchment following the procedure described in Section 3.2. For each unit, from the $C N$ values, maximal potential retention $S$ values are derived using Equation (5). Average $S$ for the entire watershed area is calculated using weighted arithmetic mean. In the following step, the corresponding initial abstraction coefficient is calculated using Equation (4), which is converted into the quadratic formula

$$
\left(-S^{2}\right) \lambda^{2}+(2 P S-Q S) \lambda+\left(Q P+Q S-P^{2}\right)=0,
$$

producing a pair of initial abstraction coefficient values for each event. From these, the final selection is carried out following the assumption that the lowest nonnegative value must be chosen. Numerically, the solution of the quadratic equation is correct. However, initial abstraction coefficient $\lambda$ must be higher than or equal to zero. In case of two non-negative roots, choosing the higher one causes initial abstraction Ia being too high, resulting in zero direct runoff generated as the condition from Equation (4) is not met.

The determination of $S$ values and subsequent calculation (Equation [6]) were conducted twice: (1) Taking into consideration the AMC classes (i.e., using $C N_{I}, C N_{I I}$ and $C N_{I I I}$ ); and (2) neglecting $A M C$ classes and using only $\mathrm{CN}_{I I}$, assuming that the AMC determination might not be a deciding factor in calculating direct runoff. 


\section{Discrete $\lambda$}

This procedure's objective was to identify a discrete representative $\lambda$ for a watershed calculated as mean and median of values obtained using Equation (6). Mean and median $\lambda$ were calculated for the entire training dataset of events and for clusters delimited by the cluster analysis.

\section{Interpolated $\lambda$}

This procedure's objective was to express $\lambda$ as a linear function of $P$ [66], instead of using a single value. The regression equations were derived using $\lambda: P$ plots. Again, the calculations were carried out with and without determination of AMC.

\subsection{3. $\lambda$ Modifications Not Dependent on Tabulated CNs}

\section{Event Analysis}

This procedure was an inverted process. The maximum potential retention, $S$, and $\lambda$ were calculated on the basis of rainfall and runoff parameters. The calculation included the following steps:

1. The total runoff $Q$ and the initial abstraction $I a$ were calculated using the procedures described above (Section 3.3).

2. The maximum potential retention, $S$, was an unknown parameter that was calculated using equation

$$
S=\frac{(P-I a)^{2}}{Q}-(P-I a),
$$

obtained by modifying Equation (4).

3. The initial abstraction coefficient $\lambda$ values were determined by dividing Ia by $S$ for each rainfall-runoff event. Mean and median $\lambda$ were calculated for each experimental watershed.

4. Regression of $S$, according to $P_{10 d}$, was calculated and used for the validation together with mean and median $\lambda$.

\section{Model Fitting}

Model fitting is an iterative least-squares procedure for determining a pair of $\lambda$ and $S$ such that the sum of the squared differences between the runoff observed and modelled

$$
\sum\left[Q-\frac{(P-\lambda S)^{2}}{(P+(1-\lambda) S)}\right]^{2}
$$

as a minimum. The computation of the model-fitting procedure was carried out using a loop-based script in Python 3.7.

\subsection{Comparison of Estimated Runoff}

For each experimental catchment, a training dataset of events was chosen to identify the key relationships characterising the $\mathrm{CN}$ method's proper setting. The remaining events were used for the parameter validation.

The quality of the runoff levels estimated by the modified CN method was evaluated by means of Nash-Sutcliffe model efficiency coefficient (NSE) (9), and bias (e) (10).

NSE is given as

$$
N S E=1-\frac{\sum\left(Q_{p i}-Q_{i}\right)^{2}}{\sum\left(Q_{i}-Q_{a}\right)^{2}}
$$


in which $Q_{p i}$ is the $i$-th modelled runoff depth, $Q_{i}$ is the $i$-th observed runoff depth and $Q_{a}$ is the mean observed runoff depth.

Bias $(e)$ is given as:

$$
e=\frac{\sum_{i=1}^{n}\left(Q_{p i}-Q_{i}\right)}{n} .
$$

NSE can range from $-\infty$ to 1 . An NSE equal to 1 expresses a perfect match of the modelled and observed values. An NSE $\geq 0.5$ indicates a very good prediction ability for the model. A lower NSE indicates a worse performance by the simulations. The $e$ is the average difference between the modelled and predicted runoff, thereby expressing the model's under- or over-estimating tendencies.

\subsection{HEC-HMS Simulations}

To test the applicability of the modified SCS-CN parameters for simulation of surface runoff, HEC-HMS 4.3 software was used. The simulations' aim was to verify the model's ability to deliver a runoff volume/level that did not differ from the observed one by more than $10 \%$, with an NSE $\geq 0.500$ (i.e., corresponding to the observed hydrograph's time course). Such simulations are viewed as sufficiently accurate. The computations were carried out only in the NE catchment, which is relatively small $\left(A=2.8 \mathrm{~km}^{2}\right)$, thereby allowing for better simulation of the surface runoff and identifying the surface-runoff simulations' response to changes in individual parameters provided in Table 3.

Table 3. Overview of methods employed in surface runoff simulations using HEC-HMS.

\begin{tabular}{|c|c|c|}
\hline & Method & Parameter \\
\hline Loss & SCS Curve Number & $\begin{array}{l}\text { Initial abstraction (mm) } \\
\text { Curve Number (-) } \\
\text { Impervious (\%) }\end{array}$ \\
\hline Transform & Clark Unit Hydrograph & $\begin{array}{c}\text { Time of concentration }(\mathrm{hr}) \\
\text { Storage coefficient }(\mathrm{hr})\end{array}$ \\
\hline & Baseflow & $\begin{array}{c}\text { Initial discharge }\left(\mathrm{m}^{3} / \mathrm{s}\right) \\
\text { Recession constant }(-) \\
\text { Ratio (-) }\end{array}$ \\
\hline
\end{tabular}

The catchment was split into three sub-basins. Calibration was carried out for two types of runoff events: (1) Those with a gradual onset, and (2) those with both a rapid onset and rapid recession limb.

The initial abstraction, $I a$, was calculated using the curve numbers estimated for the sub-basins through the method described in Section 3.3, the $\lambda$ values from the original SCS-CN method $(\lambda=0.2)$ and the median $\lambda$ values $(\lambda=0.0142)$ from the analysis of which the results are provided in Section 4.2 The percentage of impervious surfaces (buildings and sealed roads) was calculated using ESRI ArcGIS 10.7 software. Time of concentration, $T_{c}$, was calculated using Dingman's [77] formula,

$$
T_{\mathcal{C}}=1.67 \frac{3.281 L^{0.8}(0.0394 A+1)^{0.7}}{1900 \sqrt{Y}},
$$

in which $L$ is the longest flow distance path in a sub-basin $(\mathrm{m}), A$ is the sub-basin's area $\left(\mathrm{km}^{2}\right)$ and $Y$ is mean slope (\%). Dingman's formula (11) commonly is used in calculations by the Czech Hydrometeorological Institute (CHMI).

The initial discharge at each sub-basin's outlet was calculated using the main outlet's value according to the percentage of the sub-basin areas in the entire NE catchment. The remaining parameters (i.e., storage coefficient, recession constant and ratio) were set so that the calibration delivered the best possible result expressed by the bias of the runoff volume/level and NSE. Calibration coefficients were calculated for $I a, C N$ and $T_{c}$ as rates of the calibrated values to the original ones. 
Finally, two sets of these values were available: (1) For the runoff events with slow onset, and (2) for runoff events with rapid onset.

In the subsequent step, two verification events were chosen-one with a slower rising limb and another with rapid onset. Having known the $P_{5 d}\left(A M C\right.$, respectively), the original $C N$, I $a$ and $T_{c}$ values were used for both $\lambda=0.2$ and $\lambda=0.0142$, corresponding to each verification event's year. These values were multiplied by the calibration coefficients acquired in the calibration simulations. The storage coefficient, the recession constant and the ratio were calculated in the calibrations.

\section{Results}

\subsection{Influencing Parameters}

\subsubsection{Principal Component Analysis}

To reveal various rainfall and runoff parameters' influence on runoff response to rainfall at event level, principal component analysis (PCA) and cluster analysis were conducted for the studied watersheds.

The PCA analyses' outputs are presented in Figure 3. Table 4 provides an overview of the variability percentages that the first two principal components (PC1 and PC2) explain, including all input parameters' loading values in relation to PC1 and PC2. The variability percentages explained by PC1 and PC2 differ between the studied catchments. In the FU catchment, PC1 showed a value of over $71 \%$ and PC2 less than $14 \%$. In the other catchments, PC1 and PC2 percentage differences were not as big. The least difference was recorded in the KO-1 catchment (PC1 49\%, PC2 40\%). The vectors' orientation in Figure 3 and the loading values in Table 4 indicate that $P_{10 d}$ and $P_{5 d}$ present the most influential parameters in the direction of $\mathrm{PC} 1$, with maximal rain intensity and $P$ being the most influential parameters in the direction of $\mathrm{PC} 2$. The KO-1 catchment has an opposite arrangement, as maximal rain intensity and $P$ have the highest loading values in PC1 and $P_{10 d}$ and $P_{5 d}$ in PC2. This might be caused by the high percentage of arable land with presence of tile drainage system [78]. In such environment, $P_{10 d}$ and $P_{5 d}$ do not play the most influential role. Instead, direct runoff formation is dominated by the rain intensity along with $P$. Higher rain intensity produces faster and higher surface runoff and vice versa. This applies in general, but is probably accentuated in this specific catchment, making it different from the other ones.

To sum up, PCA indicates that $P_{10 d}$ and $P_{5 d}$ are the most influential parameters. The effects from maximal rain intensity and $P$, the other two most influential parameters, can be viewed as opposites, as they act along PC2.

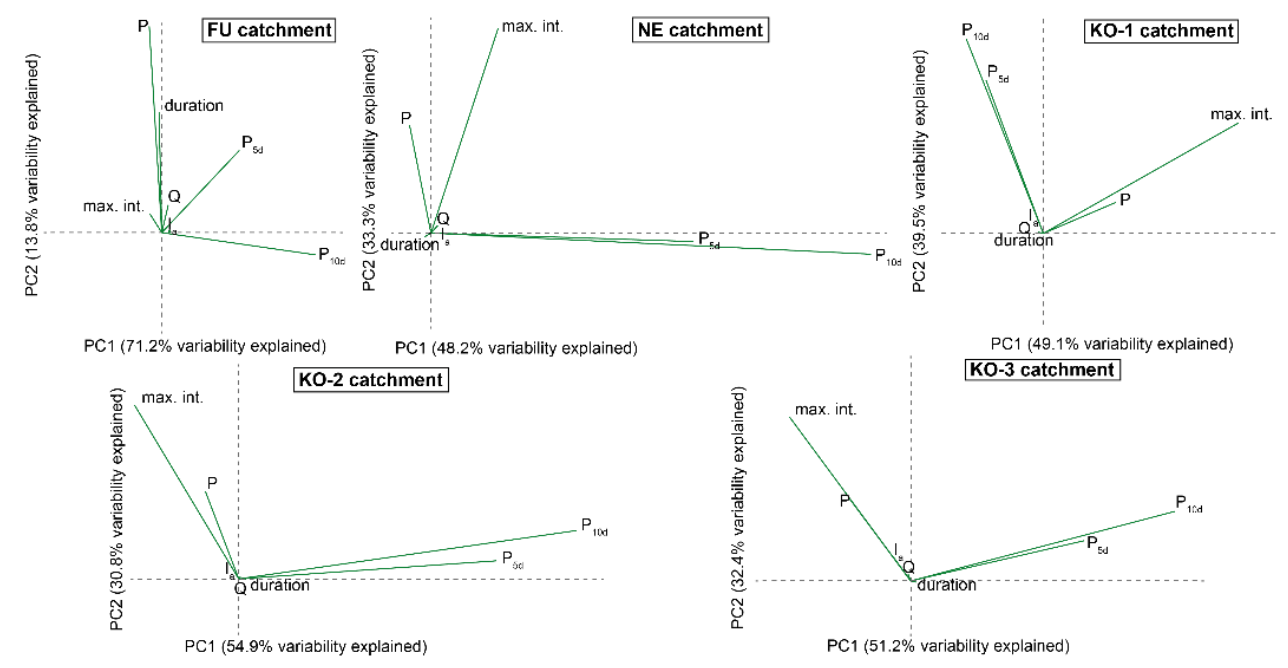

Figure 3. Principal component analysis PCA conducted for rainfall-runoff events in the experimental catchments. 
Table 4. Quantitative outputs of the principal component analysis (PCA) for each study catchment: Percentage of variability explained by PC1 and PC2 along with the loading values for each input parameter.

\begin{tabular}{ccccccccccc}
\hline $\begin{array}{c}\text { Sub-Catchment } \\
\text { Explained }\end{array}$ & \multicolumn{2}{c}{ FU } & \multicolumn{2}{c}{ NE } & \multicolumn{2}{c}{ KO-1 } & \multicolumn{2}{c}{ KO-2 } & \multicolumn{2}{c}{ KO-3 } \\
Variability & $\mathbf{7 1 . 2} \%$ & $\mathbf{1 3 . 8} \%$ & $\mathbf{4 8} \mathbf{2} \%$ & $\mathbf{3 3 . 3} \%$ & $\mathbf{4 9 . 1} \%$ & $\mathbf{3 9 . 5} \%$ & $\mathbf{5 4 . 9} \%$ & $\mathbf{3 0 . 8} \%$ & $\mathbf{5 1 . 2} \%$ & $\mathbf{3 2 . 4} \%$ \\
\hline$P$ & -0.07 & 0.81 & -0.04 & 0.46 & 0.32 & 0.11 & -0.08 & 0.44 & -0.18 & 0.41 \\
duration & -0.02 & 0.47 & -0.01 & -0.02 & -0.02 & 0.00 & 0.02 & 0.00 & 0.02 & -0.01 \\
$P_{5 d}$ & 0.45 & 0.32 & 0.51 & -0.04 & -0.25 & 0.56 & 0.59 & 0.09 & 0.50 & 0.20 \\
$P_{10 d}$ & 0.89 & -0.09 & 0.85 & -0.09 & -0.34 & 0.71 & 0.77 & 0.24 & 0.77 & 0.34 \\
max. int. & -0.07 & 0.07 & 0.13 & 0.88 & 0.85 & 0.40 & -0.24 & 0.86 & -0.35 & 0.81 \\
$Q$ & 0.04 & 0.11 & 0.01 & 0.03 & 0.00 & 0.00 & 0.00 & 0.01 & -0.01 & 0.04 \\
Ia & -0.01 & 0.01 & 0.00 & 0.02 & 0.00 & 0.01 & -0.01 & 0.02 & -0.05 & 0.11 \\
\hline
\end{tabular}

\subsubsection{Cluster Analysis}

Using the methodology introduced by Pham et al. (2005), the optimal number of clusters was determined to be two for the experimental watersheds. Subsequently, non-hierarchical k-means clustering was conducted. Mean and median values of variables in the delimited clusters are listed in Table 5. A difference in $P_{5 d}$ and $P_{10 d}$ between the delimited clusters in the studied watersheds is apparent. Such a finding corresponds to the output of the cluster analysis. Given that $P_{10 d}$ was identified as the most important factor, $P_{10 d}$ threshold values were calculated for the catchments to be able to distinguish the cluster to which an event belongs. To determine thresholds, the mean of the upper quartile $P_{10 d}$ from the cluster with smaller $P_{10 d}$ and the lower quartile $P_{10 d}$ from the other cluster (i.e., a cluster with higher $P_{10 d}$ ) was calculated. The same procedure was applied to calculate the corresponding $P_{5 d}$ thresholds, as the $P_{5 d}$ normally is used in the traditional SCS-CN procedure to determine AMC classes. The $P_{5 d}$ and $P_{10 d}$ thresholds were $26 \mathrm{~mm}$ and $47 \mathrm{~mm}$ in the FU catchment, $18 \mathrm{~mm}$ and $39 \mathrm{~mm}$ in the NE catchment, $35 \mathrm{~mm}$ and $42 \mathrm{~mm}$ in the KO-1 catchment, $41 \mathrm{~mm}$ and $50 \mathrm{~mm}$ in the KO-2 catchment and $20 \mathrm{~mm}$ and $28 \mathrm{~mm}$ in the KO-3 catchment. For each catchment, these $P_{5 d}$ and $P_{10 d}$ thresholds were used for separation of rainfall-runoff events into two groups in analyses across the paper.

Table 5. Mean and median values of events' parameters (duration $(\mathrm{h}), P(\mathrm{~mm}), P_{5 d}(\mathrm{~mm}), P_{10 d}(\mathrm{~mm})$, max. int. $(\mathrm{mm} / \mathrm{h}), Q(\mathrm{~mm}), I a(\mathrm{~mm}))$ in the delimited clusters for the experimental catchments.

\begin{tabular}{|c|c|c|c|c|c|c|c|c|c|c|c|c|c|c|c|}
\hline & \multicolumn{3}{|c|}{ FU } & \multicolumn{3}{|c|}{ NE } & \multicolumn{3}{|c|}{ KO-1 } & & \multicolumn{2}{|c|}{ KO-2 } & \multicolumn{3}{|c|}{ KO-3 } \\
\hline & & Mean & Med. & & Mean & Med. & & Mean & Med. & & Mean & Med. & & Mean & Med. \\
\hline duration & & 12.02 & 10.00 & & 3.62 & 2.67 & & 4.00 & 2.92 & & 3.50 & 2.67 & & 3.47 & 2.75 \\
\hline P & & 17.4 & 14.0 & & 10.8 & 6.9 & & 17.1 & 11.5 & & 13.9 & 10.0 & & 14.3 & 10.0 \\
\hline$P_{5 d}$ & 字 & 25.7 & 20.1 & $\infty$ & 16.6 & 11.3 & เి & 18.4 & 11.9 & 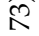 & 14.7 & 9.2 & $\infty$ & 14.4 & 8.7 \\
\hline$P_{10 d}$ & $\mathrm{II}$ & 42.9 & 35.3 & II & 30.1 & 22.2 & II & 28.8 & 21.2 & "I & 25.0 & 18.8 & II & 27.2 & 19.9 \\
\hline max. int. & $=$ & 10.68 & 8.30 & $=$ & 14.40 & 7.80 & & 23.12 & 13.80 & $=$ & 19.11 & 12.60 & $=$ & 19.88 & 12.30 \\
\hline$Q$ & & 1.830 & 0.337 & & 0.448 & 0.076 & & 0.316 & 0.081 & & 0.293 & 0.069 & & 0.567 & 0.101 \\
\hline Ia & & 1.5 & 0.8 & & 1.7 & 1.4 & & 2.4 & 1.8 & & 0.8 & 0.0 & & 2.4 & 1.1 \\
\hline duration & & 12.03 & 9.00 & & 3.81 & 2.92 & & 3.69 & 2.92 & & 3.41 & 2.80 & & 3.37 & 2.67 \\
\hline P & $=$ & 18.5 & 14.1 & $\infty$ & 11.3 & 7.1 & $\infty$ & 17.8 & 11.4 & $\infty$ & 14.0 & 10.0 & $\widehat{a}$ & 16.3 & 10.8 \\
\hline$P_{5 d}$ & ल & 17.1 & 13.3 & $\begin{array}{c}n \\
11 \\
\|\end{array}$ & 8.3 & 6.7 & Th & 11.8 & 10.2 & 0 & 11.2 & 8.5 & in & 7.0 & 5.4 \\
\hline$P_{10 d}$ & $\Xi$ & 26.2 & 26.4 & $\Xi$ & 18.1 & 17.0 & $\Xi$ & 22.4 & 18.8 & $\Xi$ & 21.8 & 17.2 & $\Xi$ & 13.7 & 13.7 \\
\hline max. int. & - & 11.43 & 8.90 & - & 13.70 & 7.80 & 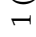 & 24.40 & 14.40 & - & 19.43 & 12.90 & - & 22.80 & 12.60 \\
\hline$Q$ & $\dot{u}$ & 1.152 & 0.301 & نे & 0.319 & 0.065 & चे & 0.308 & 0.056 & $\dot{u}$ & 0.246 & 0.052 & $\dot{0}$ & 0.633 & 0.090 \\
\hline Ia & & 1.6 & 0.8 & & 1.7 & 1.5 & & 2.4 & 1.6 & & 0.8 & 0.0 & & 2.9 & 1.2 \\
\hline duration & & 12.00 & 10.50 & & 3.15 & 2.33 & & 5.81 & 5.17 & & 4.67 & 2.67 & & 3.67 & 2.83 \\
\hline P & ક & 15.1 & 12.4 & ๙ิ & 9.7 & 5.5 & (2) & 12.9 & 11.7 & เก & 12.5 & 10.8 & ని & 10.5 & 8.8 \\
\hline$P_{5 d}$ & 4 & 44.7 & 42.7 & i & 37.7 & 37.4 & $\begin{array}{l}\infty \\
\text { ॥ }\end{array}$ & 58.2 & 60.3 & 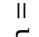 & 63.2 & 63.2 & II & 28.2 & 25.3 \\
\hline$P_{10 d}$ & $\Xi$ & 79.9 & 76.6 & $\Xi$ & 60.4 & 59.5 & $\Xi$ & 67.5 & 67.4 & 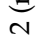 & 68.0 & 69.9 & है & 52.3 & 42.5 \\
\hline max. int. & $\sim$ & 9.03 & 7.00 & $\sim$ & 16.17 & 9.00 & ? & 15.60 & 7.80 & $\dot{0}$ & 14.90 & 10.80 & $\stackrel{\sim}{-}$ & 14.55 & 11.40 \\
\hline Q & نे & 3.332 & 2.406 & نا & 0.773 & 0.097 & च & 0.361 & 0.208 & & 0.925 & 0.514 & & 0.444 & 0.178 \\
\hline Ia & & 1.3 & 1.0 & & 1.6 & 1.3 & & 2.6 & 2.4 & & 0.8 & 0.2 & & 1.4 & 0.7 \\
\hline
\end{tabular}




\subsection{Tabulated CN-Based $\lambda$ Modification}

The first way to improve the $\mathrm{CN}$ method is through incorporation of tabulated $\mathrm{CNs}$ [65] along with modified $\lambda$ values. The following calculations were carried out with and without taking into consideration the separation of rainfall events according to the $P_{5 d}$ and $P_{10 d}$ thresholds determined through the cluster analysis. Moreover, AMC classes' effect was examined by performing the calculations with and without the AMC classification. Modified $\lambda$ was calculated as a discrete value and as functionally dependent on $P$.

\subsubsection{Discrete $\lambda$}

For the comparison, the original $\mathrm{CN}$ method with $\lambda=0.2$ was applied, and the results showed that in this form, the model mostly was unable to deliver good results, except for the KO-1 catchment (for $\lambda=0.2$ NSE $=0.861$ ). Partial improvements were recorded in simulations with the AMC classification omitted. Only in the KO-1 catchment, the accuracy reduced significantly (NSE dropped from 0.861 to -16.769 , see Table 6 and Figure S1a,b). It is important to emphasize that the traditional CN method is limited in terms of "zero runoff" cases since the condition from Equation (4) is often not met due to high $\lambda$, and also due to the effect of spatial variability in catchments [30,31], which, however, was not addressed in the present study. The relatively good results for the traditional $\mathrm{CN}$ method needs to be confronted with high numbers of events for which the model was unable to deliver non-zero direct runoff. This is apparent in Figure S1a,b. Specifically, the number of non-zero cases ranged from 0 to 13 for simulations with AMC classified and from 7 to 27 for simulations with AMC implicitly set as normal $(\mathrm{AMC}=\mathrm{II})$.

To improve the $\mathrm{CN}$ method's performance, mean and median $\lambda$ values were determined in the training datasets as a whole and in groups separated according to the $P_{5 d}$ and $P_{10 d}$ thresholds. Generally, the analysis revealed that in most instances $\lambda$ was lower than 0.2. In the unseparated datasets, mean $\lambda$ ranged from 0.0365 to 0.1623 and median $\lambda$ from 0.0142 to 0.0913 . Except for one catchment (KO-1), the reduction of $\lambda$ led to improvements in estimated runoff, since NSE exceeded 0.500 , thereby indicating sufficient accuracy. In simulations with separation of events according to $P_{5 d}$ and $P_{10 d}$ thresholds, a greater variability in $\lambda$ values existed, ranging from 0.0183 to 0.4231 . Despite the expectation that this greater diversification of $\lambda$ values will lead to more accurate results (in relation to the non-cluster-based approach-all, i.e., without the separation according to $P_{5 d}$ and $\left.P_{10 d}\right)$, this assumption only partially was fulfilled. In the FU catchment, the cluster-based approach improved all direct runoff estimates. In the NE catchment, better results were delivered for median. In catchments KO-2 and KO-3, only simulations with median $\lambda$ applied in events separated according to $P_{10 d}$ led to increased accuracy in estimates. No positive response was recorded in simulations using the modified $\lambda$ values in the KO-1 catchment (NSE ranged from -7.993 to 0.323 ).

In examining the calculations while not considering AMC classes (AMC implicitly was set to II, normal), higher accuracy in calculated runoff was recorded in the original $\mathrm{CN}$ approach, except for the KO-1 catchment. The cluster-based simulations led to better runoff matches only in the FU and NE catchments. In the other catchments, accuracy even decreased significantly.

In summary, the results show that replacing $\lambda$ originally set to 0.2 with lower values can lead to improvements in direct-runoff simulations. However, the KO-1 catchment was the only one in which no positive effect from the $\lambda$ modification was recorded. High $e$ values indicated the model's over-estimating tendency in this specific catchment, probably due to improper $\mathrm{CN}$ determination. This might have been caused by the high percentage (97.3\%) of arable land along with the presence of the tile drainage systems [78]. In other words, the results revealed quite specific hydrologic conditions in KO-1 catchment compared to the other two KO catchments. Moreover, this well illustrates that $\mathrm{CN}$ determination based solely on the prescribed criteria [65] might be misleading. Instead, it should take into consideration all available data on an area of interest. 
It should be noted that some studies stated that the modification of $\lambda$ should be accompanied by a corresponding adjustment in $C N$ or $S$, separately $[2,16]$. Therefore, such an approach also was used in this research, but this did not lead to better results than those presented above.

Table 6. Accuracy of direct runoff simulations using mean and median $\lambda$ values in the experimental catchments with (antecedent moisture condition (AMC) all) and without (AMC = II) determination of AMC classes. NSE $\geq 0.500$ indicating sufficient accuracy are highlighted.

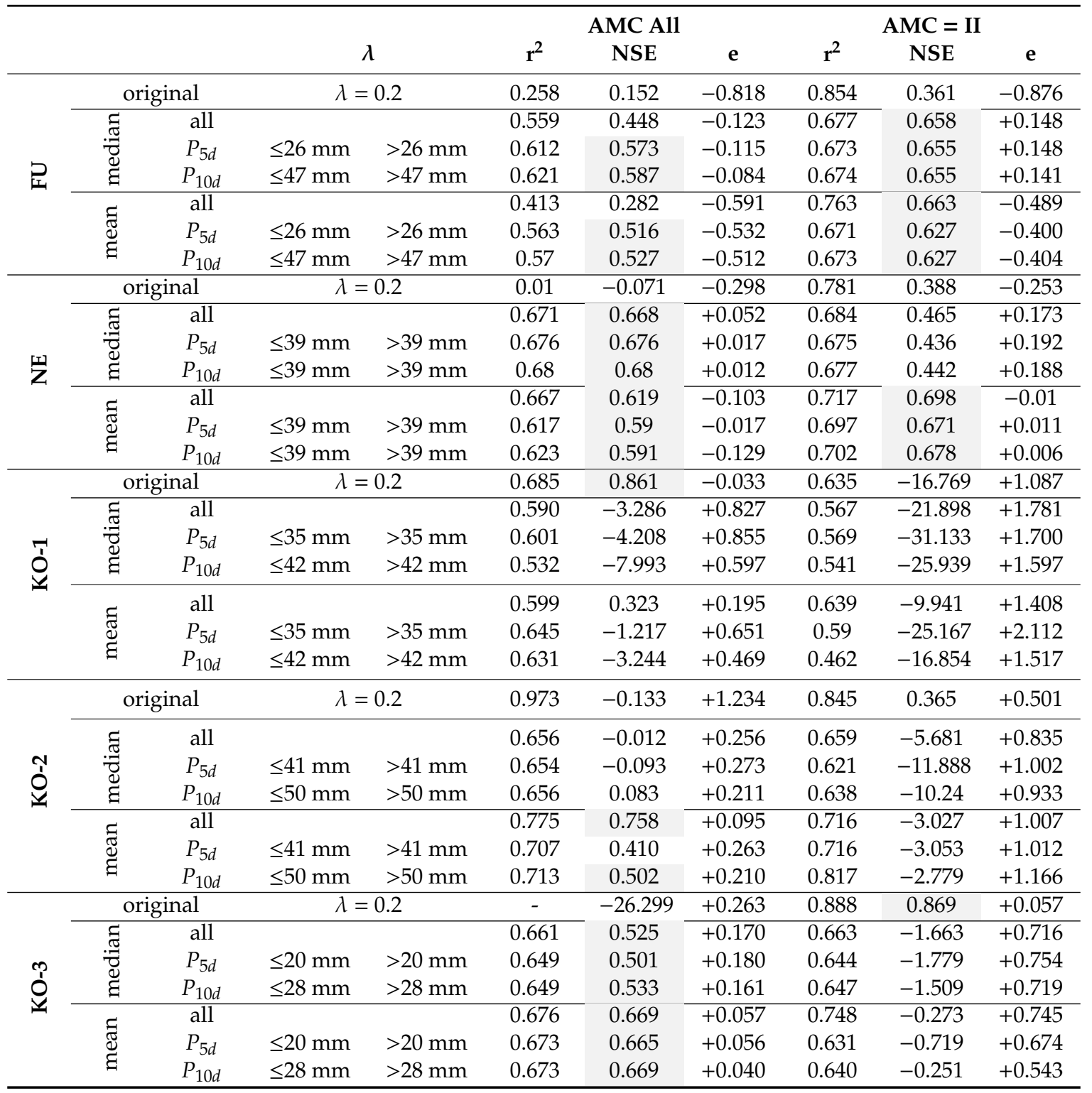

\subsubsection{Interpolated $\lambda$}

Besides discrete values, $\lambda$ can be expressed as a linear function of $P[66,67]$. The linear $\lambda-P$ regressions were calculated for each catchment with and without AMC classification. Analogously to the previous approach (Section 4.2.1), regression equations were calculated for datasets delimited by the $P_{5 d}$ and $P_{10 d}$ thresholds determined through cluster analysis. All the regression equations are provided in Figure 4 and Table 7. 
FU (AMC all)

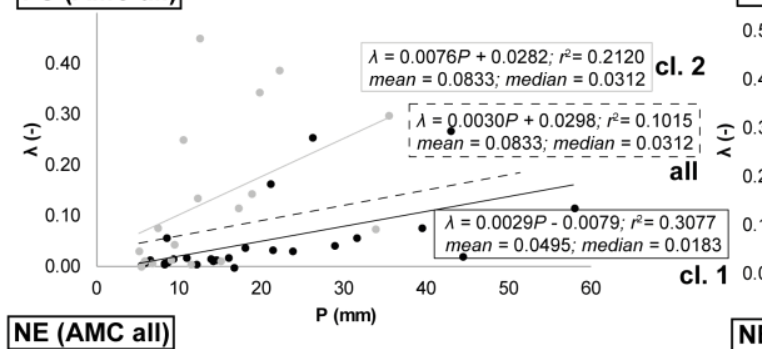

NE (AMC all)

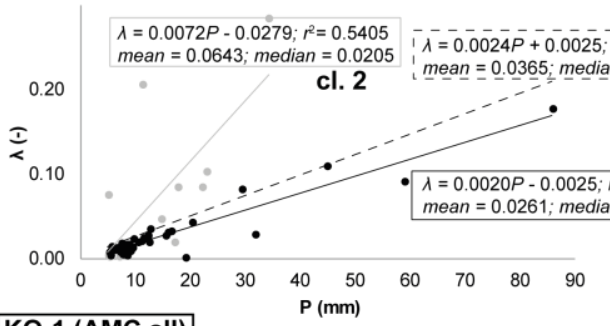

KO-1 (AMC all)

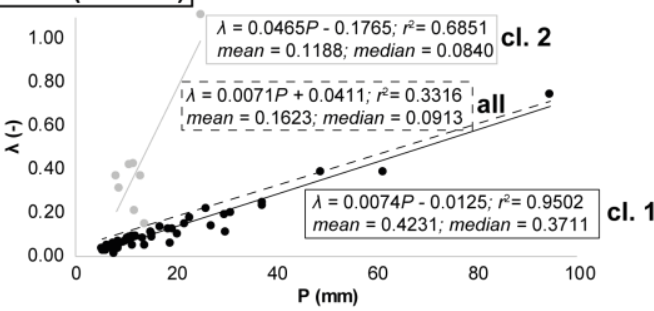

\section{KO-2 (AMC all)}

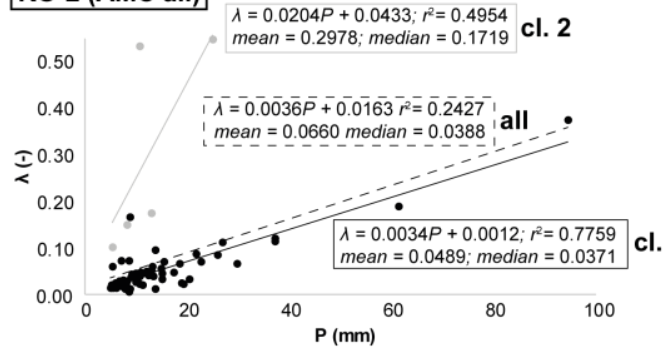

KO-3 (AMC all)

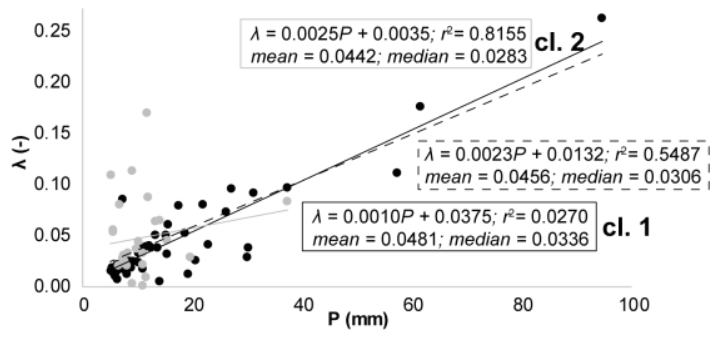

\section{FU (AMC = II)}

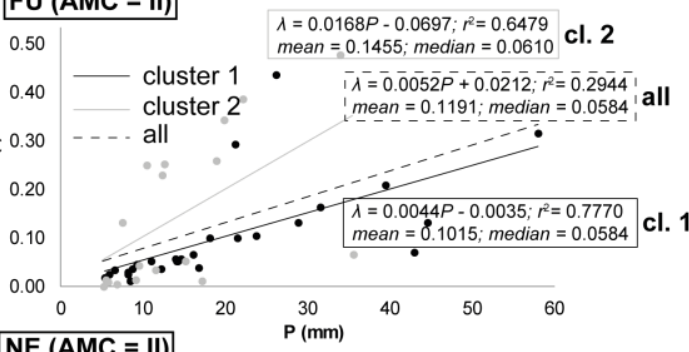

NE (AMC = II)
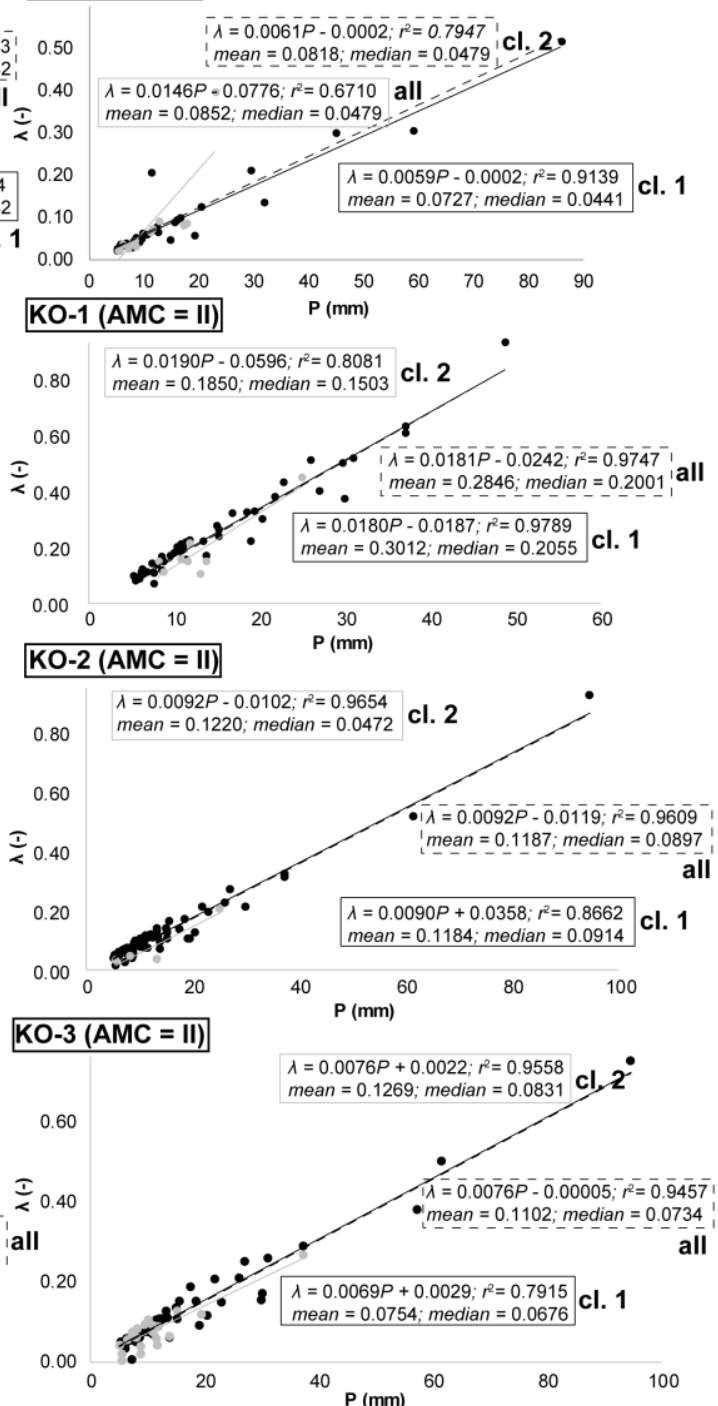

Figure 4. Initial abstraction coefficient $\lambda$ expressed as linear function of precipitation height $P$ for the experimental catchments and for AMC classified (AMC all) and normal only (AMC = II). 
Table 7. Accuracy of direct runoff simulations using regressions of $\lambda$ according to $P$ in the experimental catchments with $(\mathrm{AMC}$ all $)$ and without $(\mathrm{AMC}=\mathrm{II})$ determination of AMC classes. NSE $\geq 0.500$ indicating sufficient accuracy are highlighted.

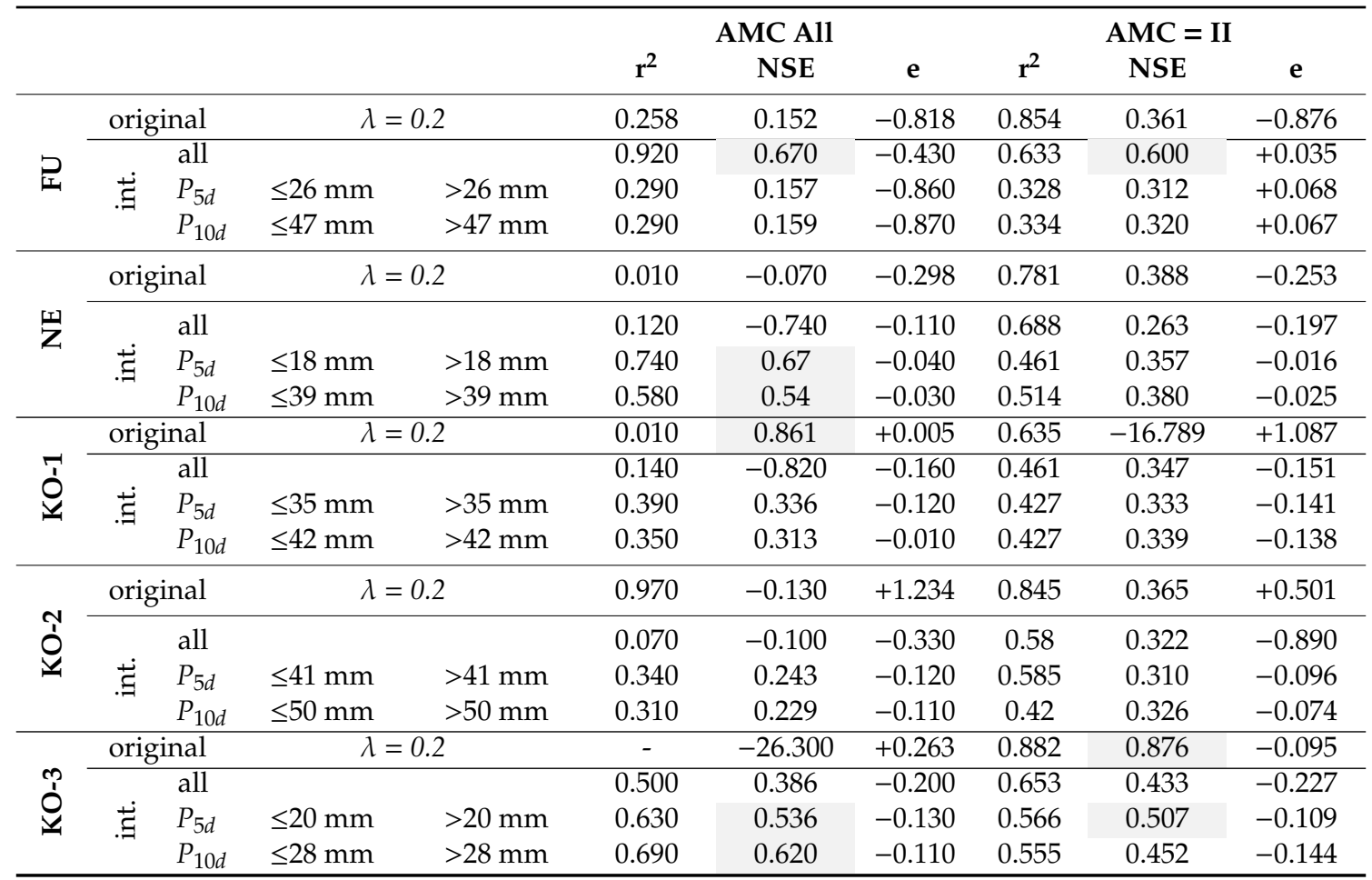

Generally, application of the $\lambda-P$ linear regressions increased the runoff estimates' accuracy. However, for higher $Q$ the estimates showed systematically underestimating tendency (see Figure 5). Moreover, the effect differed between the experimental catchments. In the FU catchment, the best performance ( $N S E=0.670$ ) was recorded with using regression for the entire dataset (all-i.e., without the separation according to $P_{5 d}$ and $P_{10 d}$ ). In the other four catchments, the cluster-based regressions (i.e., those considering the separation according to $P_{5 d}$ and $P_{10 d}$ ) delivered the best outputs. However, only in catchments NE and KO-3 did NSE values exceed 0.500 (specifically, 0.670 and 0.540 in the NE catchment, 0.536 and 0.620 in the KO-3 catchment). Applying the all regression in the NE catchment reduced NSE from -0.070 (original $\mathrm{CN}$ method) to -0.740 . In the KO-3 catchment, the effect was opposite as NSE increased from -26.3 to 0.386 . In the remaining catchments $\mathrm{KO}-1$ and $\mathrm{KO}-2$ the results were similar, but NSE values did not indicate sufficient accuracy. Better results were obtained from simulations that omitted the AMC classification in general (see Figure S2), but NSE exceeded 0.500 only in the FU catchment (all regression-NSE $=0.600$ ) and the KO-3 catchment (cluster-based $P_{5 d}$ regression $\left.-N S E=0.507\right)$.

Compared with the "discrete $\lambda$ " approach, the regression-based simulation appears to be more stable in terms of overall enhancement of the $\mathrm{CN}$ method's performance. The results indicate that $\lambda$ should be a variable and event-dependent value. However, the irregular arrangement of the results hints that reliable usage of robust regression-based approach will require a subsequent detailed research of more rainfall-runoff data from various watersheds. 

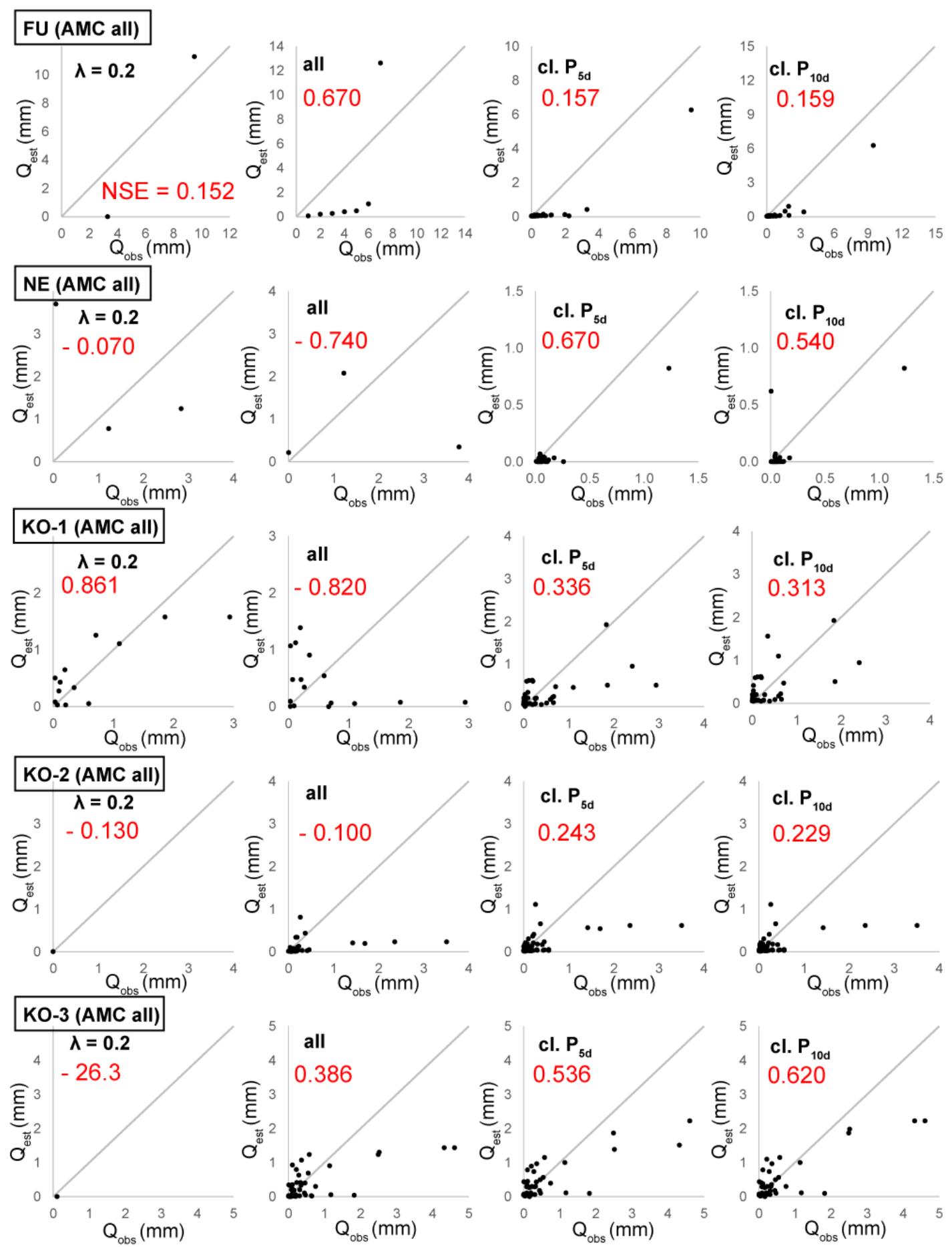

Figure 5. Comparison of observed direct runoff heights $(\mathrm{mm})$ with those simulated in the experimental catchments using regressions of $\lambda$ according to $P$ for events with AMC classified (AMC all). Comparison of direct runoff estimates with AMC not classified $(\mathrm{AMC}=\mathrm{II})$ is provided in Figure S2.

\subsection{Approaches Not Dependent on Tabulated CNs}

\subsubsection{Event Analysis}

Unlike the previous analyses, this approach does not start with determining CNs in the watersheds. Instead, it is based on analysing the rainfall-runoff events' parameters $(P, I a, Q)$, from which $\lambda$ and $S$ are derived. This procedure aims to analyse the array of $\lambda$ and $S$ to reveal a natural relation between them. 
PCA revealed that $P_{10 d}$ poses the most important variable in the arrangement of events (see Figure 3). Therefore, regressions for $S$ according to $P_{10 d}$ were calculated for each catchment. Mean and median $\lambda$ identified in the training dataset were used (see Table 8).

Table 8. Accuracy of direct runoff simulations using regressions of $S$ according to $P_{10 d}$ (event analysis) in the experimental catchments using $\lambda=0.2$, mean and median $\lambda$. NSE $\geq 0.500$ indicating sufficient accuracy are highlighted.

\begin{tabular}{|c|c|c|c|c|c|c|}
\hline Catchment & & & Regression of $\mathrm{S}$ & $\mathbf{r}^{2}$ & NSE & e \\
\hline \multirow{3}{*}{ FU } & orig. & 0.2 & \multirow{3}{*}{$\begin{array}{c}S=13987.982 P_{10 d^{-1.154}} \\
\left(r^{2}=0.3731\right)\end{array}$} & - & 0.129 & -0.820 \\
\hline & mean & 0.0183 & & 0.84 & 0.683 & -0.120 \\
\hline & median & 0.0029 & & 0.84 & 0.692 & +0.219 \\
\hline \multirow{3}{*}{ NE } & orig. & 0.2 & \multirow{3}{*}{$\begin{array}{c}S=-318.995 \ln \left(P_{10 d}\right)+1584,638 \\
\left(r^{2}=0.3573\right)\end{array}$} & 0.37 & 0.371 & -0.350 \\
\hline & mean & 0.0077 & & 0.75 & 0.592 & +0.206 \\
\hline & median & 0.0026 & & 0.74 & 0.636 & -0.100 \\
\hline \multirow{3}{*}{ KO-1 } & orig. & 0.2 & \multirow{3}{*}{$\begin{aligned} S= & 9641.4 P_{10 d}{ }^{-0.859} \\
& \left(r^{2}=0.3473\right)\end{aligned}$} & 0685 & 0.861 & -0.033 \\
\hline & mean & 0.0086 & & 0.6 & 0.536 & -0.040 \\
\hline & median & 0.0012 & & 0.67 & 0.511 & +0.070 \\
\hline \multirow{3}{*}{ KO-2 } & orig. & 0.2 & \multirow{3}{*}{$\begin{array}{c}S=1843.7 e^{-0.025 P 10 d} \\
\quad\left(r^{2}=0.1750\right)\end{array}$} & - & -0.133 & +1.234 \\
\hline & mean & 0.0064 & & 0.91 & 0.622 & -0.170 \\
\hline & median & 0.0 & & 0.85 & 0.758 & -0.040 \\
\hline \multirow{3}{*}{ KO-3 } & orig. & 0.2 & \multirow{3}{*}{$\begin{array}{c}S=874.92 e^{-0.026 P 10 d} \\
\quad\left(r^{2}=0.2671\right)\end{array}$} & - & -26.3 & +0.263 \\
\hline & mean & 0.0129 & & 0.85 & 0.159 & -0.780 \\
\hline & median & 0.0010 & & 0.77 & 0.521 & -0.260 \\
\hline
\end{tabular}

Unlike the tabulated $C N$-based approaches, the event analysis delivered more accurate direct runoff estimates (see Table 8, Figure 6). Again, the KO-1 catchment showed lower NSE values (0.536 and 0.511 ) than for the original $C N$ method applied (0.861). On the other hand, the informative value of NSE in case of the traditional CN method with $\lambda=0.2$ was addressed already (Section 4.2.1). Despite the overall improvement of the estimates, there is an underestimating tendency for higher $Q$ evident, similar to the one seen in the tabulated $\mathrm{CN}$-based approach.
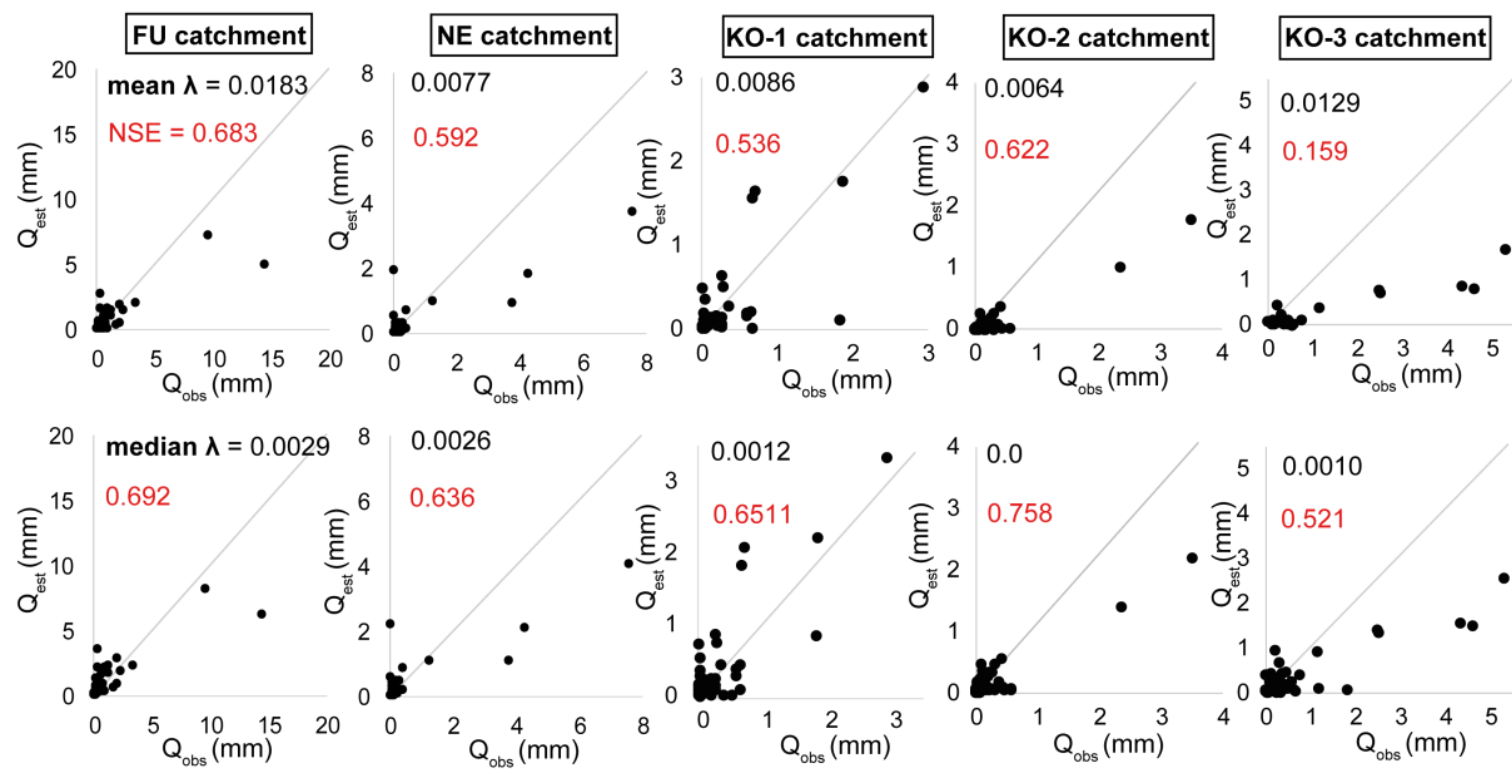

Figure 6. Comparison of observed direct runoff heights with those simulated in the experimental catchments using regressions of $S$ according to $P_{10 d}$ (event analysis) with application of mean and median $\lambda$. 
The results presented in Table 8 show that using $P_{10 d}-S$ regressions, along with modified $\lambda$, improved direct-runoff estimates' accuracy in all five studied catchments. NSE increased (for $\lambda=0.2$, NSE ranged from -2.012 to 0.129 ) both with mean $\lambda$ (NSE ranged from 0.159 to 0.683 ) and median $\lambda$ (NSE ranged from 0.511 to 0.758 ). The observed-vs-modelled runoffs are plotted in Figure 6.

\subsubsection{Model Fitting}

The iterative model-fitting procedure was applied to training datasets in all studied catchments to identify pairs of $S$ and $\lambda$ values. As in previous analyses, computations were performed with and without the clustering (separation), according to the $P_{5 d}$ and $P_{10 d}$ thresholds. The $S: \lambda$ pairs are provided in Table 9. Verification has shown that using the identified $S: \lambda$ pairs leads to enhancement of estimated direct runoff, compared with those calculated through the original CN method. However, performance differs among catchments (Table 10, Figure 7). For simulations without the separation (all), NSE ranged from 0.146 to 0.585 . NSE exceeded 0.500 in the FU and KO-3 catchments. For the $P_{5 d}$-based separation, NSE ranged from 0.362 to 0.671 , and NSE was higher than 0.500 in the FU and KO-3 catchments. Finally, for the $P_{10 d}$-based separation, NSE ranged from 0.391 to 0.768 , with NSE exceeding 0.500 in the $\mathrm{NE}$ and KO-3 catchments. In addition, here, the underestimating tendency is apparent for higher $Q$.

Table 9. Pairs of $S$ and $\lambda$ values identified by the model fitting iterative procedure in the experimental catchments. Clustered (cl.) and non-clustered (all) events were used. The cluster delimitation was done using the $P_{5 d}$ and $P_{10 d}$ thresholds.

\begin{tabular}{|c|c|c|c|c|}
\hline & & & \multicolumn{2}{|c|}{$\mathrm{S}(\mathrm{CN}) / \lambda$} \\
\hline \multirow{2}{*}{ FU } & all & & \multicolumn{2}{|c|}{$371.5 \mathrm{~mm}(40.64) / 0.0$} \\
\hline & $\mathrm{cl}$. & $\begin{array}{l}P_{5 d} \\
P_{10 d}\end{array}$ & $\begin{array}{l}\leq 26 \mathrm{~mm}: 687.5 \mathrm{~mm} \mathrm{(26.98)/0.0} \\
\leq 47 \mathrm{~mm}: 596.9 \mathrm{~mm} \mathrm{(29.85)/0.0}\end{array}$ & $\begin{array}{l}\geq 26 \mathrm{~mm}: 138.9 \mathrm{~mm}(64.65) / 0.0 \\
\geq 47 \mathrm{~mm}: 97.9 \mathrm{~mm}(72.18) / 0.0\end{array}$ \\
\hline \multirow[b]{2}{*}{ NE } & all & & \multicolumn{2}{|c|}{$1093.0 \mathrm{~mm}(18.86) / 0.0$} \\
\hline & $\mathrm{cl}$. & $\begin{array}{l}P_{5 d} \\
P_{10 d}\end{array}$ & $\begin{array}{l}\leqq 18 \mathrm{~mm}: \\
\leqq 39 \mathrm{~mm}: \\
1154.4 \mathrm{~mm}(10.03) / 0.0\end{array}$ & $\begin{array}{l}>18 \mathrm{~mm}: 12.9 \mathrm{~mm}(95.17) / 1.0 \\
>39 \mathrm{~mm}: 87.7 \mathrm{~mm}(74.33) / 0.0667\end{array}$ \\
\hline \multirow[b]{2}{*}{ KO-1 } & all & & \multicolumn{2}{|c|}{$3949.4 \mathrm{~mm}(6.04) / 0.0$} \\
\hline & $\mathrm{cl}$. & $\begin{array}{l}P_{5 d} \\
P_{10 d}\end{array}$ & $\begin{array}{l}\leqq 35 \mathrm{~mm}: 4015.7 \mathrm{~mm}(5.95) / 0.0 \\
\leq 42 \mathrm{~mm}: 4152.3 \mathrm{~mm}(5.75) / 0.0\end{array}$ & $\begin{array}{c}>35 \mathrm{~mm}: \\
42 \mathrm{~mm}: \\
1299.9 \mathrm{~mm}(21.82) / 0.0 \\
\end{array}$ \\
\hline \multirow[b]{2}{*}{ KO-2 } & all & & \multicolumn{2}{|c|}{$2967.0 \mathrm{~mm}(7.89) / 0.0$} \\
\hline & $\mathrm{cl}$. & $\begin{array}{l}P_{5 d} \\
P_{10 d}\end{array}$ & $\begin{array}{l}\leq 41 \mathrm{~mm}: 3037.0 \mathrm{~mm}(7.72) / 0.0 \\
\leq 50 \mathrm{~mm}: 3125.7 \mathrm{~mm}(7.52) / 0.0\end{array}$ & 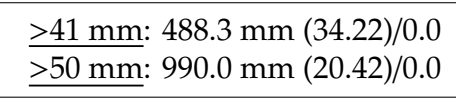 \\
\hline \multirow{2}{*}{ KO-3 } & all & & \multicolumn{2}{|c|}{$905.0 \mathrm{~mm}(21.92) / 0.0$} \\
\hline & $\mathrm{cl}$. & $\begin{array}{l}P_{5 d} \\
P_{10 d}\end{array}$ & $\begin{array}{l}\leq 20 \mathrm{~mm}: \\
\leq 28 \mathrm{~mm}: \\
923.3 \mathrm{~mm}(22.01) / 0.0 \\
\end{array}$ & 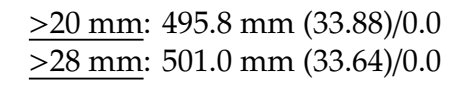 \\
\hline
\end{tabular}

Table 10. Accuracy of direct runoff simulations using pairs of $S$ and $\lambda$ identified by means of model fitting procedure. NSE $\geq 0.500$ indicating sufficient accuracy are highlighted.

\begin{tabular}{|c|c|c|c|c|c|c|c|c|c|c|c|c|c|c|c|}
\hline & \multicolumn{3}{|c|}{ FU Catchment } & \multicolumn{3}{|c|}{ NE Catchment } & \multicolumn{3}{|c|}{ KO-1 Catchment } & \multicolumn{3}{|c|}{ KO-2 Catchment } & \multicolumn{3}{|c|}{ KO-3 Catchment } \\
\hline & \multirow{2}{*}{ All } & \multicolumn{2}{|c|}{ cl. } & \multirow{2}{*}{ All } & \multicolumn{2}{|c|}{ cl. } & \multirow{2}{*}{ All } & \multicolumn{2}{|c|}{ cl. } & \multirow{2}{*}{ All } & \multicolumn{2}{|c|}{ cl. } & \multirow{2}{*}{ All } & \multicolumn{2}{|c|}{ cl. } \\
\hline & & $P_{5 d}$ & $P_{10 d}$ & & $P_{5 d}$ & $P_{10 d}$ & & $P_{5 d}$ & $P_{10 d}$ & & $P_{5 d}$ & $P_{10 d}$ & & $P_{5 d}$ & $P_{10 d}$ \\
\hline $\mathrm{r}^{2}$ & 0.642 & 0.56 & 0.508 & 0.271 & 0.799 & 0.813 & 0.402 & 0.494 & 0.666 & 0.665 & 0.521 & 0.573 & 0.747 & 0.796 & 0.718 \\
\hline NSE & 0.585 & 0.55 & 0.488 & 0.247 & 0.463 & 0.763 & 0.173 & 0.362 & 0.496 & 0.146 & 0.453 & 0.391 & 0.547 & 0.671 & 0.581 \\
\hline e & -0.062 & -0.149 & +0.075 & -0.195 & +0.075 & -0.055 & -0.253 & -0.21 & -0.193 & -0.149 & -0.167 & -0.17 & +0.642 & -0.193 & -0.222 \\
\hline
\end{tabular}




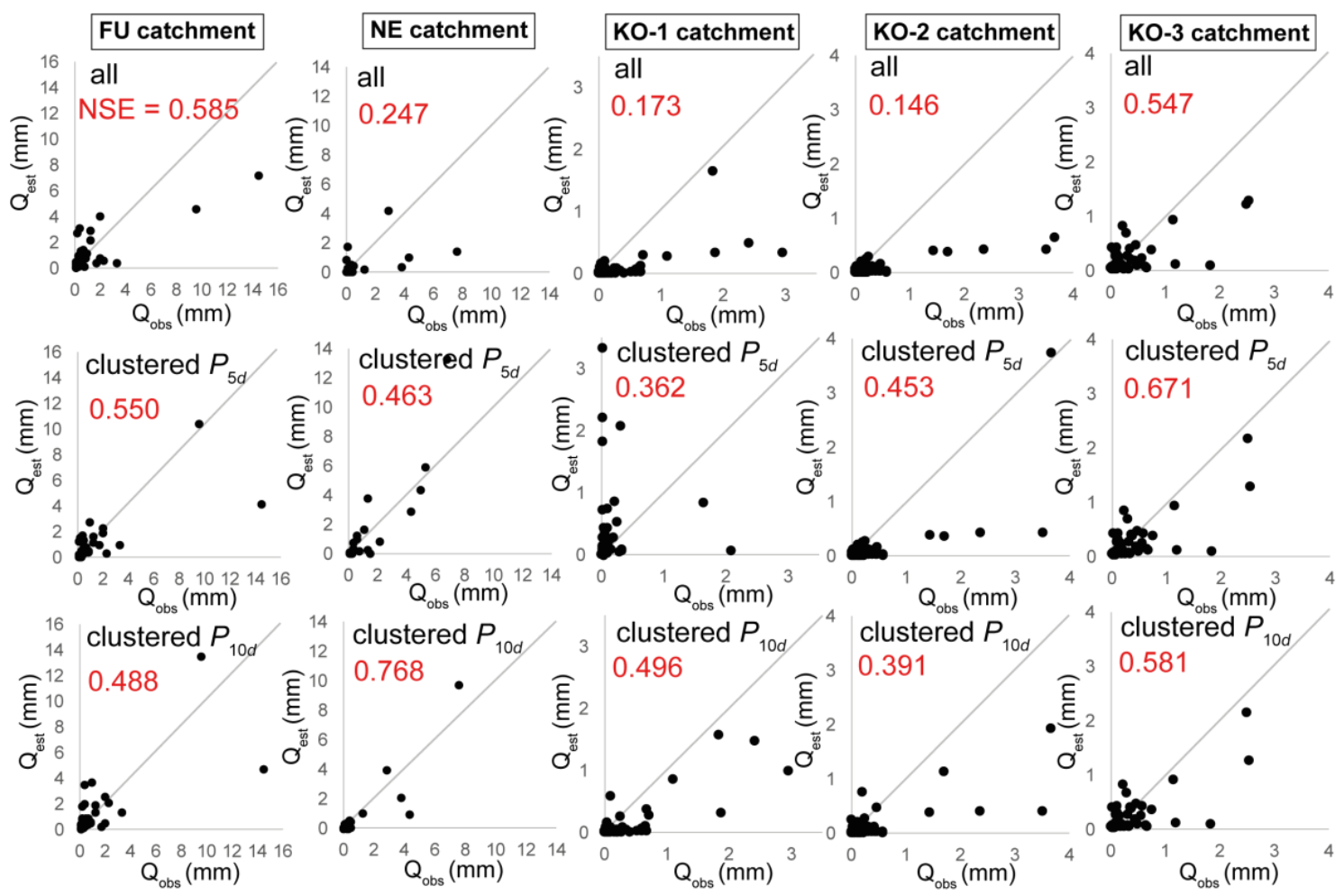

Figure 7. Comparison of observed direct runoff heights with those simulated using pairs of $S$ and $\lambda$ identified by means of model fitting procedure. The validation was carried out both with (all) and without delimitation of clusters according to $P_{5 d}$ (clustered $\left.P_{5 d}\right)$ and $P_{10 d}$ (clustered $P_{10 d}$ ).

\subsection{HEC-HMS Simulations}

To simulate a surface-runoff process using HEC-HMS, calibration was conducted for two types of events: (1) Those with a slowly rising limb of the hydrograph, and (2) those with a rapid onset. In the calibrations, all parameters' values (see Section 3.5 were optimised, and calibration coefficients were calculated for $I a, C N$ and $T_{\mathcal{C}}$ (Table 11). The remaining parameters' values were taken as they had been calculated in the calibrations.

Table 11. Calibration coefficients for transformation of $I a, C N$ and $T_{c}$ in the three sub-basins of the NE catchment. The coefficients are provided for runoff events with both slow and rapid onset and for the $\lambda=0.2$ and $\lambda=0.0142$.

\begin{tabular}{cccccccc}
\hline & & \multicolumn{3}{c}{ Slower Onset } & \multicolumn{3}{c}{ Rapid Onset } \\
\hline \multirow{2}{*}{$\lambda$} & Sub-Basin & $\boldsymbol{I} \boldsymbol{a}$ & $\boldsymbol{C N}$ & $\boldsymbol{T}_{\boldsymbol{c}}$ & $\boldsymbol{I} \boldsymbol{a}$ & $\boldsymbol{C N}$ & $\boldsymbol{T}_{\boldsymbol{c}}$ \\
\hline \multirow{3}{*}{0.2} & NE-1 & 0.235 & 1.000 & 1.963 & 0.349 & 1.010 & 0.214 \\
& NE-2 & 0.186 & 1.000 & 1.364 & 0.348 & 1.010 & 0.225 \\
& NE-3 & 0.192 & 1.000 & 3.284 & 0.353 & 1.325 & 0.307 \\
\hline \multirow{3}{*}{0.0142} & NE-1 & 0.778 & 1.015 & 1.136 & 0.134 & 0.670 & 0.210 \\
& NE-2 & 0.778 & 1.015 & 0.794 & 0.136 & 0.669 & 0.147 \\
& NE-3 & 0.750 & 1.014 & 1.504 & 0.179 & 0.850 & 0.348 \\
\hline
\end{tabular}

The HEC-HMS simulations indicate that changes in all surface-runoff-driving parameters led to improved results. For the event with the rising limb of the hydrograph rising rather slowly, significant improvement was achieved even for $\lambda=0.2$ with modified parameters. In the original setting, the bias was $-52.29 \%$ and NSE was -4.655 (see Figure $8 \mathrm{a}$ ). In the simulation that employed the modified parameters, bias was only $-3.17 \%$, and NSE reached 0.918 (see Figure $8 b$ ). For the same event, 
a simulation using $\lambda=0.0142$ with the original parameters' values delivered solid output, with bias at $-7.01 \%$ and NSE reaching 0.845 (see Figure $8 \mathrm{c}$ ). Finally, computations using $\lambda=0.0142$ and the recalculated parameters led to improvement in the simulation, as bias fell to $-2.12 \%$, and NSE increased to 0.912 (see Figure $8 \mathrm{~d}$ ).
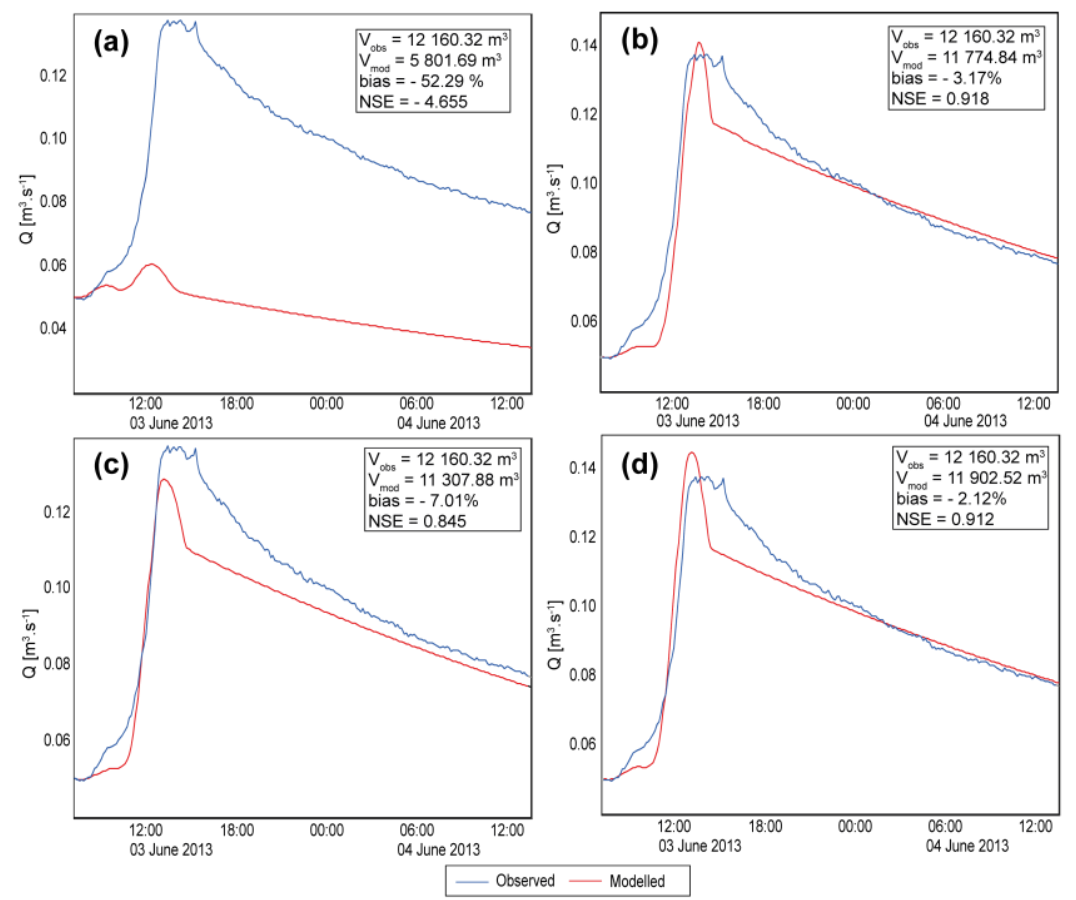

Figure 8. Verification of surface runoff simulations of a runoff event with a slower onset in the NE catchment using the HEC-HMS software. The simulations were computed using original $\mathrm{I} a, \mathrm{CN}$ and $T_{\mathcal{c}}$ values corresponding to $\lambda=0.2(\mathbf{a})$, modified $I a, C N$ and $T_{\mathcal{c}}$ values corresponding to $\lambda=0.2(\mathbf{b})$, original $I a, C N$ and $T_{\mathcal{c}}$ values corresponding to $\lambda=0.0142$ (c) and finally modified $I a, C N$ and $T_{c}$ values corresponding to $\lambda=0.0142$ (d). The model's performance is expressed by the bias of runoff heights and Nash-Sutcliffe model efficiency (NSE) coefficient.

The simulation of runoff response with a rapid onset was less accurate, as indicated in Figure 9. The computation employing $\lambda=0.2$ with the original setting of the surface-runoff-driving parameters was insufficient (see Figure 9a). After recalculating the parameters, accuracy increased $(N S E=0.408)$, but absolute bias worsened. The modelled runoff depicted in Figure $9 \mathrm{~b}$ shows an approximation to the real data in terms of temporal course. Analogous use of $\lambda=0.0142$ delivered a more pronounced improvement in the modelled runoff, with bias falling from 55\% to 3\%, and NSE increasing from -0.194 to 0.695 (Figure 9c,d).

Bearing in mind that the number of simulations by the HEC-HMS performed in this study is low, one should avoid general interpretations. Nevertheless, the presented results outline how reducing I improves the model's ability to deliver more accurate output, which is significantly more pronounced in the case of slow onset runoff, in which both the temporal course and runoff volume/level matched well with real runoff. In the case of rapid onset events, reducing $\lambda$ from 0.2 to 0.0142 played a more significant role, as the best simulation was the one with $\lambda=0.0142$ and recalculated parameters. However, the simulated hydrograph did not match well with the real results (Figure 9d). This indicates that the HEC-HMS simulation of such types of runoff events can deliver sufficiently accurate hydrographs in terms of runoff volume/level, although the culmination is inaccurate. 

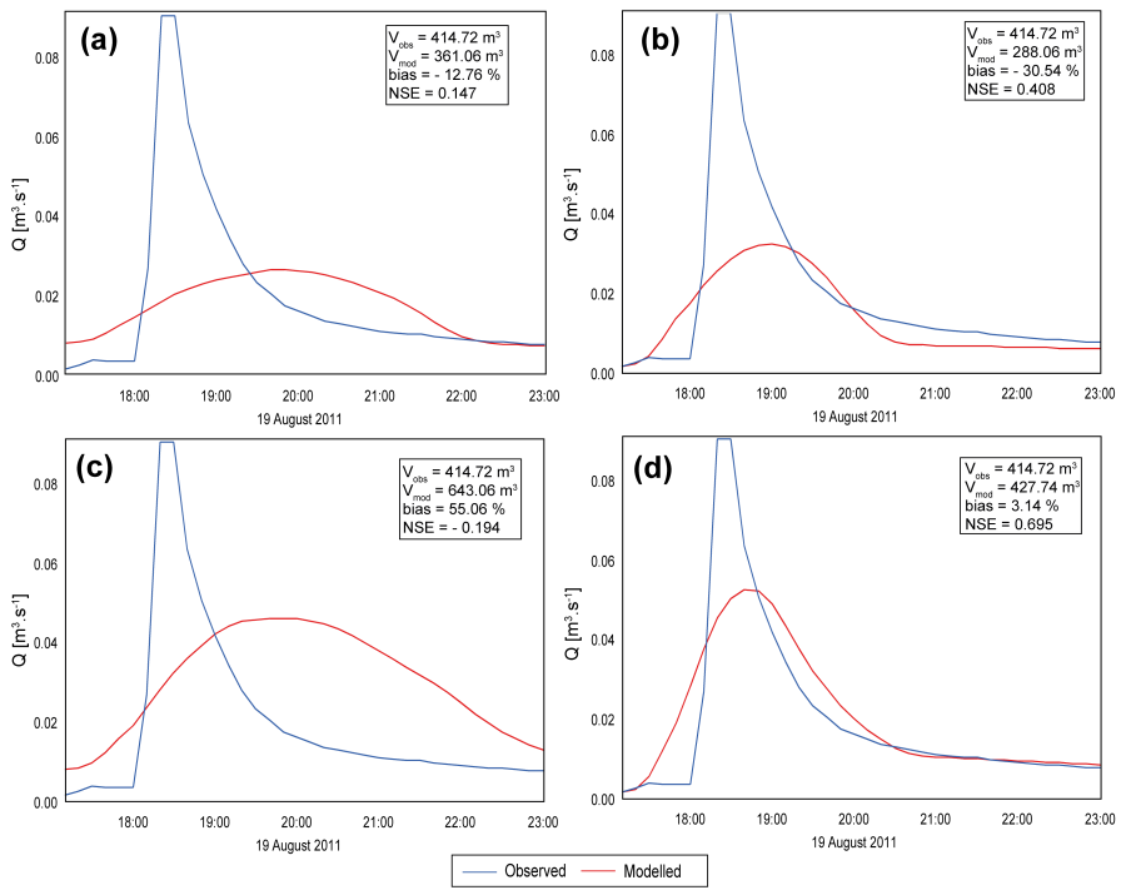

Figure 9. Verification of surface runoff simulations of a runoff event with a rapid onset in the NE catchment using the HEC-HMS software. The simulations were computed using original $\mathrm{I} a, \mathrm{CN}$ and $T_{c}$ values corresponding to $\lambda=0.2(\mathbf{a})$, modified $I a, C N$ and $T_{c}$ values corresponding to $\lambda=0.2(\mathbf{b})$, original $I a, C N$ and $T_{c}$ values corresponding to $\lambda=0.0142$ (c) and modified $I a, C N$ and $T_{c}$ values corresponding to $\lambda=0.0142$ (d). The model's performance is expressed by the bias of runoff heights and NSE coefficient.

\section{Discussion and Conclusions}

Experience from various watersheds worldwide has highlighted the sensitivity of runoff to the initial abstraction coefficient $[2,24,64]$. In this study, initial abstraction coefficients $\lambda$ were estimated for five experimental catchments in the Czech Republic, which well reflect the physiographic conditions (in terms of soil and geomorphology) in the Central European watersheds, using various approaches. From a methodological perspective, they can be divided into two types: (1) Approaches based on a classical determination of tabulated $C N$ numbers [65], and (2) those based on a $C N$-independent analysis of rainfall-runoff data. The adjusted $\lambda$ values were determined as discrete or function-dependent (interpolated). Contribution of this research lies in the comparison of different approaches of $C N$ estimations applied in various watersheds.

\subsection{Tabulated CN, Discrete $\lambda$}

When using discrete $\lambda$ values, these general conclusions based on our findings can be stated: $\lambda$ differed both between studied catchments and between events, and the original value of 0.2 should be reduced in studied catchments, except the KO- 1 catchment. Mean $\lambda$ ranged from 0.0365 to 0.8330 and median $\lambda$ from 0.0142 to 0.0913 for simulations that take the AMC classification into consideration. In simulations that omitted the AMC classification (AMC implicitly was set to II), $\lambda$ values were slightly higher. Mean $\lambda$ ranged from 0.0818 to 0.2846 , and median $\lambda$ ranged from 0.0479 to $0.2001 ; \lambda$ exceeded 0.2 in the KO-1 catchment, which is almost entirely covered by arable and land with specific infiltration conditions due to presence of tile drainage system [66], making this catchment very different from the others. The example of the KO-1 catchment well documents that correct $\mathrm{CN}$ determination must take into consideration artificial elements that are not reflected in the traditional methodology, yet their influence on runoff formation is significant. 
Generally, the obtained results correspond with those of other authors, such as Baltas et al. [62], who reported mean $\lambda=0.034$ and 0.014 for two watersheds. They attributed the various $\lambda$ results to differences in the presence of impervious formations and urban development. Similarly, Shi et al. [11] reported $\lambda$ ranging from 0.010 to 0.152 , with a median of 0.048 due to landscape and geological characteristics. Lal et al. [13] conducted research in different agricultural plots in India and found that the mean and median for $\lambda$ were 0.0 and 0.034 . Krajewski et al. [24] compared $\lambda$ values in 2 catchments in Poland and found average $\lambda=0.026$ and 0.047 .

\subsection{Tabulated $C N$, Interpolated $\lambda$}

Some approaches exist for expressing $\lambda$ as being functionally (linearly) dependent on precipitation. For example, Kohnová et al. [69] conducted research in Slovakian watersheds and expressed $\lambda$ as a linear function of precipitation for each AMC class. Moreover, they also discussed the low number of II and III AMC classes. Therefore, they stated that no apparent relationship existed between $C N$ and $\mathrm{AMC}$, and that other parameters' roles should be emphasised. Application of linear $\lambda: P$ relationships in this study increased runoff estimates' overall accuracy compared with the original $\mathrm{CN}$ method. Like the discrete $\lambda, N S E$ only exceeded 0.500 in one catchment-the KO-3 catchment with AMC classified, and in the KO-1 catchment without AMC classification. Generally speaking, the ability of $\lambda: P$ linear regressions used for runoff simulations appears to be rather weak, which can be attributed to unknown interplay among other characteristics taking part in the direct-runoff formation, or to inappropriate tabulated CNs. Moreover, a question arises of the need of training datasets large enough, from which representative regression equations can be derived. Despite the sufficient amount of training events in this study (from 44 to 80 ), there is a problem of lack of extreme/severe events, in which the runoff formation may be very specific.

Recently, a different interpolating approach has been successfully tested by Krajewski et al. [24], approximating the $\lambda-P$ relationship with an asymptotic formula. They found greater variability in $\lambda$ values for smaller $P$. After exceeding a certain threshold $P, \lambda$ approaches a constant value. The threshold depends on a catchment's characteristics, namely land cover that strongly influences the direct runoff formation or initial abstraction, separately. Based on the promising results of this asymptotic approach, the method definitely deserves to be tested in wider range of geographical conditions.

\subsection{Summary of Tabulated CN-Based Approaches}

Modification of $\lambda$ in calculations using tabulated $C N$ s led to a partial increase in the accuracy of direct-runoff estimates, but because NSE often did not exceed 0.500 , overall performance seems to be rather unambiguous. More specifically, it is apparent that the estimates for smaller $Q$ were more accurate than for those with higher $Q$. This issue might be resolved based on sophisticated statistical analyses that were beyond the scope of this study.

Both discussed approaches' inaccuracy indicates that the tabulated CNs [65] used in the Czech Republic often are not representative, thereby requiring a systematic revision that should be based on analyses of a large amount of data from various watersheds in the Central European region, ensuring the $C N$ method's robustness. Moreover, just as it seems inappropriate to use the universal initial abstraction coefficient $\lambda$ value for different river basins, it certainly would be more appropriate to use the $C N$ method, taking into account the spatio-temporal variability of runoff conditions resulting from seasonal variability in $C N$ and $\lambda$ regarding vegetation variability and distribution of soil and land use [24,30-32]. Extant studies have dealt with this issue, such as one conducted by Hawkins et al. [2], who concluded that lower CNs prevailed during the summer (growing season) and that higher CNs better represented runoff conditions during the dormant season. In a recent study by Muche et al. [79], CNs were derived using the Normalised Difference Vegetation Index (NDVI) to reflect seasonal land-use changes in the hydrologic circle. They concluded that the CN-NDVI method is a promising alternative to the traditional CN method. In the present study, the CORINE Land Cover dataset was refined using aerial images together with annual data on crop distribution on arable land, where available. It is 
reasonable to assume that by using appropriate satellite data, the estimated CNs would better represent the spatial distribution of land-cover features, vegetation and also soil moisture. However, this went beyond the scope of this research. Moreover, it should be noted that the Central European region currently is facing the bark beetle calamity and a drought affecting large areas of forest stands (mostly with spruces). This should be taken into account during determination of CNs, although the calamity did not affect the studied catchments. In this regard, it should also be added that the issue of a single $C N$ value characterising the entire catchment's conditions has been addressed by Soulis and Valiantzas $[30,31]$ who implemented a two-CN system approach in heterogeneous watersheds and improved the CN method's performance. Even in a watershed affected by massive changes caused by a forest fire, this approach performed well [32]. Thus, efficient methods exist, offering opportunity to be used in the process of new $C N$ determination (revision), not only in the Czech Republic.

\subsection{Tabulated CN-Independent Approaches}

To estimate optimal $\lambda$ and $S$ values, two methods without using tabulated $C N$ s were applied: (1) Event analysis based on analysing individual events' rainfall-runoff parameters, and (2) model fitting - an iterative numerical procedure searching for a pair of $\lambda$ and $S$ values that best describe a particular catchment's runoff conditions.

The event analysis yielded the best results from all the methods compared in this research. In all studied catchments, the application of $S-P_{10 d}$ regressions combined with mean (ranging from 0.0064 to 0.0129 ) and median $\lambda$ (ranging from 0.0 to 0.0029 ) led to significant increases in estimated direct-runoff accuracy. With one exception (KO-3 catchment with mean $\lambda$ applied), NSE always exceeded 0.500.

The model-fitting procedure also produced more accurate outputs compared with the original $\mathrm{CN}$ method, both with and without using the clustering (separation) according to the $P_{5 d}$ and $P_{10 d}$ thresholds. NSE exceeded 0.500 in only two out of the five studied catchments. This probably is caused by the fact that using a single pair of $\lambda$ and $S$ values that universally represent runoff conditions in a catchment in a wide range of rainfall and land-cover arrangements is questionable [24,30]. Another problem resides in the lack of events with high $Q$, of which the behaviour is strongly variable, and thus significantly influences the calculation of the $\lambda: S$ pairs.

\subsection{HEC-HMS Simulations Using Adjusted $\lambda$ and CN}

Application of adjusted $\lambda$ values in HEC-HMS shows that using lower $\lambda$ leads to improvements in simulated runoff accuracy, but a difference exists between hydrographs with slow and rapid onsets: Both yielded sufficiently accurate results in terms of runoff volume. However, within the hydrograph with rapid onset, the model was unable to match the culmination discharge. This might indicate a lower performance in the HEC-HMS SCS-CN-based simulations to model events with fast runoff response, especially flash floods, in terms of peak discharge, which often is the parameter of the main interest. At the same time, it should be emphasised that general interpretations would require an analysis on a representative dataset of rainfall-runoff events. In this present study, the aim was to examine preliminarily the applicability of modified $\lambda$ values within HEC-HMS software.

\subsection{Summary}

The present study shows that the original CN methodology without adjustments to local conditions is hardly applicable in the geographical conditions of the experimental watersheds. Both $C N$ and $\lambda$ values should be based on site-specific characteristics, i.e., on rainfall-runoff data observations, hinting that they should be viewed as flexible regional parameters, rather than fixed values. In the studied catchments' specific natural conditions, the $\lambda$ appears mostly to be considerably lower than the original value of 0.2 . As the $\mathrm{CN}$ method frequently is used in long-term and event-based runoff simulations, erosion modelling and wide range of other applications, appropriate modifications of the method, such as those presented in this study, can contribute significantly to improvements in their outputs. It is the authors' intention to extent the present research and take up the unresolved problems, such as the 
systematic underestimation of direct runoff for events with higher runoff observed. Moreover, testing the possibilities of revisiting $C N$ determination, mainly with regard to watersheds' heterogenity, as well as investigation of the regionalised concepts in the natural and agricultural conditions of the Czech Republic and neighbouring countries appears to be a challenging issue deserving our attention. This study's outcomes may serve as a preliminary basis for subsequent activities addressing the aforementioned tasks.

Supplementary Materials: The following are available online at http:/www.mdpi.com/2073-4441/12/7/1964/s1, Figure S1a: Comparison of observed direct runoff heights $(\mathrm{mm})$ with those simulated in the experimental catchments using discrete mean and median $\lambda$ values with AMC classified (AMC all), Figure S1b: Comparison of observed direct runoff heights $(\mathrm{mm})$ with those simulated in the experimental catchments using discrete mean and median $\lambda$ values with AMC implicitly set as normal (AMC $=$ II), Figure S2: Comparison of observed direct runoff heights (mm) with those simulated in the experimental catchments using regressions of $\lambda$ according to $P$ for events with AMC classified (AMC all) and implicitly set as normal (AMC = II).

Author Contributions: Conceptualisation, M.C.; methodology, M.C., M.Š.M.; validation, M.C.; formal analysis, M.C., M.Š.M.; P.F.; investigation, M.C.; writing-original draft preparation, M.C., M.Š.M.; writing-review and editing, M.C., M.Š.M., P.F., P.K.; visualisation, M.C. All authors have read and agreed to the published version of the manuscript.

Funding: This research was funded by the DEPARTMENT OF GEOGRAPHY, FACULTY OF SCIENCE, MASARYK UNIVERSITY, grant number MUNI/A/1251/2019, T. G. MASARYK WATER RESEARCH INSTITUTE, internal grant number 1628 and 3600.52.27/2020 and by the MINISTRY OF AGRICULTURE OF THE CZECH REPUBLIC, grant number MZE RO0218.

Acknowledgments: The authors would like to thank the Povodí Odry State Enterprise and Research Institute for Soil and Water Conservation for providing the input rainfall and runoff data. The authors also would like to thank the anonymous reviewers for their constructive comments and recommendations, which helped to improve the paper.

Conflicts of Interest: The authors declare no conflict of interest.

\section{References}

1. Bonta, J.V. Determination of Watershed Curve Number Using Derived Distributions. J. Irrig. Drain. Eng. 1997, 123, 28-36. [CrossRef]

2. Woodward, D.E.; Hawkins, R.H.; Jiang, R.; Hjelmfelt, A.T., Jr.; Van Mullem, J.A.; Quan, Q.D. Runoff curve number method: Examination of the initial abstraction ration. In Proceedings of the World Water and Environmental Resources Congress, Philadelphia, PA, USA, $23-26$ June 2003; Bizier, P., De Barry, P., Eds.; pp. 691-700.

3. USDA. Soil Conservation Service, National Engineering Handbook Supplement: Supplement A, Hydrology; USDA: Washington, DC, USA, 1956.

4. USDA. Soil Conservation Service, National Engineering Handbook. Section 4: Hydrology; USDA: Washington, DC, USA, 1972; p. 762.

5. USDA. Urban Hydrology for Small Watersheds, 2nd ed.; Technical Release 55; USDA: Washington, DC, USA, 1986; p. 164.

6. USDA. National Engineering Handbook, Part 630, Hydrology; USDA: Washington, DC, USA, 2004.

7. Hawkins, R.H.; Ward, T.J; Woodwards, E.; Van Mullem, J.A. Continuing evolutioon of rainfall-runoff and the curve number precedent. In Proceedings of the 2nd Federal Inegracy Conference, Las Vegas, NV, USA, 27 June-1 July 2010.

8. Mishra, S.K.; Vijay, P.; Singh, P.K. Revisiting the Soil Conservation Service curve number method. In Proceedings of the International Conference on Water, Environment, Energy and Society, Bhopal, India, 15-18 March 2016; Singh, V.P., Yadav, S., Yadava, R.N., Eds.; Springer: Singapore, 2018; pp. 667-693.

9. Ponce, V.M.; Hawkins, R.H. Runoff curve number: Has it reached maturity? J. Hydrol. Eng. 1996, 1, 11-19. [CrossRef]

10. Satheeshkumar, S.; Venkateswaran, S.; Kannan, R. Rainfall-runoff estimation using SCS-CN and GIS approach in the Pappiredipatti watershed of the Vaniyar sub basin, South India. Mod. Earth Sys. Environ. 2017, 3. [CrossRef] 
11. Shi, Z.H.; Chen, L.D.; Fang, N.F.; Qin, D.F.; Cai, C.F. Research on the SCS-CN initial abstraction ratio using rainfall-runoff event analywsis in the Three Gorges Area, China. Catena 2009, 77, 1-7. [CrossRef]

12. Jacobd, J.H.; Srinivasan, R. Effects of curve number modification on runoff estimation using WSR-88D raifall data in Texas watersheds. J. Soil Water Conserv. 2005, 60, 274-279.

13. Lal, M.; Mishra, S.K.; Pandey, A. Physical verification of the effect of land features and antecedent moisture on runoff curve number. Catena 2015, 133, 318-327. [CrossRef]

14. Springer, E.P.; McGurk, B.J.; Hawkins, R.H.; Coltharp, G.B. Curve numbers from watershed data. In Proceeding of the Symposium on Watershed Management, Boise, ID, USA, 21-23 July 1980; ASCE: New York, NY, USA, 1980; pp. 938-950.

15. Mishra, S.K.; Chaudhary, A.; Shrestha, R.K.; Pandey, A.; Lal, M. Experimental Verification of the Effect and Land Use on SCS Runoff Curve Number. Water Resour. Manag. 2014, 28, 3407-3416.

16. Hawkins, R.H.; Ward, T.J.; Woodwards, E.; Van Mullem, J.A. Curve Number Hydrology: State of the Practice; ASCE: Reston, VA, USA, 2009; p. 106.

17. Jha, M.K.; Chovdary, V.M.; Kulkarni, Y.; Mal, B.C. Rainwater harvesting planning using geospatial techniques and multicriteria decision analysis. Res. Conserv. Recycl. 2014, 83, 96-111. [CrossRef]

18. Sharpley, A.N.; Williams, J.R. EPIC Erosion/Productivity Impact Calculator: 1. Model Documentation. In USA Department of Agriculture Technical Bulletin No. 1768; Government Printing Office: Washington, DC, USA, 1990.

19. Ajmal, M.; Moon, G.; Ahn, J.; Kim, T. Investigation of SCS-CN and its inspired modified models for runoff estimation in South Korean watersheds. J. Hydro-Environ. Res. 2015, 9, 592-603. [CrossRef]

20. Ajmal, M.; Khan, T.A.; Kim, T.W. A CN-Based Ensembled Hydrological Model for Enhanced Watershed Runoff Prediction. Water 2016, 8, 20. [CrossRef]

21. Mishra, S.K.; Singh, V.P. SCS-CN-based hydrologic simulation package. In Mathematical Models in Small Watershed Hydrology; Singh, V.P., Frevert, D.K., Eds.; Water Resources Publications: Littleton, CO, USA, 2002; pp. 391-464.

22. Hjelmfelt, A.T. Ivestigation of curve number procedure. J. Hydraul. Eng. 1991, 117, 725-737. [CrossRef]

23. Randusová, B.; Marková, R.; Kohnová, S.; Hlavčová, K. Comparison of cn estimation approaches. Int. J. Eng. Sci. 2015, 1, 34-40.

24. Krajewski, A.; Sikorska-Senoner, A.E.; Hejduk, A.; Hejduk, L. Variability of the Initial Abstraction Ratio in an Urban and an Agroforested Catchment. Water 2020, 12, 471. [CrossRef]

25. Hjelmfelt, A.T. Empirical investigation of curve number technique. J. Hydraul. Div. ASCE 1980, 106, 1471-1476.

26. Hawkins, R.H. Discussion of 'Empirical Ivestigation of Curve Number Technique', by A. T. Hjelmfelt. J. Hydraul. Div. ASCE 1981, 107, 953-954.

27. Hawkins, R.H.; Hjelmfelt, A.T.; Zevenbergen, A.W. Runoff probability, relative storm depth, and runoff curve numbers. J. Irrig. Drain. Eng. 1985, 111, 330-340. [CrossRef]

28. Hawkins, R.H. 1993 Asymptotic determination of runoff curve numbers from data. J. Irrig. Dran. Div. ASCE 1993, 119, 334-345. [CrossRef]

29. Ajmal, M.; Kim, T. Quantifying excess stormwater using SCS-CN-based rainfall runoff models and different curve number determination methods. J. Irrig. Drain. Eng. 2015, 141. [CrossRef]

30. Soulis, K.X.; Valiantzas, J.D. SCS-CN parameter determination using rainfall-runoff data in heterogenous watersheds-The two-CN system approach. Hydrol. Earth Syst. Sci. 2012, 16, 1001-1015. [CrossRef]

31. Soulis, K.X.; Valiantzas, J.D. Identification of the SCS-CN Parameter Spatial Distribution Using Rainfall-Runoff Data in Heterogenous Watersheds. Water. Resour. Manage. 2013, 27, 1737-1749. [CrossRef]

32. Soulis, K.X. Estimation of SCS Curve Number variation following forest fires. Hydrol. Sci. J. 2018, 63, 1332-1346. [CrossRef]

33. Rees, H.W.; Chow, T.L.; Gregorch, E.G. Soil and crop responses to long-term potato production at a benchmark site in northwestern New Brunswick. Can. J. Soil Sci. 1988, 88, 409-422. [CrossRef]

34. Wang, X.; Liu, T.; Yang, W. Development of a robust runoff-prediction model by fusing the Rational Equation and modified SCS-CN method. Hydrol. Sci. J. 2012, 57, 1118-1140. [CrossRef]

35. Mishra, S.K.; Pandey, R.P.; Jain, M.K.; Singh, V.P. A rain duration and modified AMC-dependent SCS-CN procedure for long duration rainfall-runoff events. Water Resour. Manag. 2008, 22, 861-876. [CrossRef] 
36. Neitsch, S.L.; Arnold, J.G.; Kiniry, J.R.; Williams, J.R.; King, K.W. Soil and Water Assessment Tool (SWAT): Theoretical Documentation, Version 2000; Texas Water Resources Institute: College Station, TX, USA, 2002; p. 506.

37. Sobhani, G. A Review of Selected Small Watershed Design Methods for Possible Adoption to Iranian Conditions. Master's Thesis, Utah State University, Logan, UT, USA, 1975.

38. Mishra, S.K.; Singh, V.P.; Sansalone, J.J.; Aravamuthan, V. A modified SCS-CN method: Characterization and testing. Water Resour. Manag. 2003, 17, 37-68. [CrossRef]

39. Ponce, V.M. Engineering Hydrology, Principles and Practices; Prentice Hall: Englewood Cliffs, NJ, USA, 1989; p. 640.

40. Williams, J.R.; LaSeur, W.V. Water yield model using SCS curve numbers. J. Hydraul. Div. 1976, 102, 1241-1253.

41. Hawkins, R.H. Runoff curve numbers with varying site moisture. J. Irrig. Drain. Div. 1978, 104, 389-398.

42. Mishra, S.K.; Jain, M.K.; Singh, V.P. Evaluation of the SCS-CN-based model incorporating antecedent moisture. Water Resour. Manag. 2004, 18, 567-589. [CrossRef]

43. Mishra, S.K.; Singh, V.P. Long-term hydrological simulation based on the Soil Conservation Service curve number. Hydrol. Process. 2004, 18, 1291-1313. [CrossRef]

44. Michel, C.; Andréassian, V.; Perrin, C. Soil Conservation Service Curve Number method: How to mend a wrong soil moisture accounting procedure? Water Resour. Res. 2005, 41. [CrossRef]

45. Jain, M.K.; Durbude, D.G.; Mishra, S.K. Improved CN-based long-term hydrologic simulation model. J. Hydrol. Eng. 2012, 17, 1204-1220. [CrossRef]

46. Sahu, R.K.; Mishra, S.K.; Eldho, T.I.; Jain, M.K. An advanced soil moisture accounting, procedure for SCS curve number method. Hydrol. Process. 2007, 21, 2872-2881. [CrossRef]

47. Singh, P.K.; Mishra, S.K.; Berndtsson, R.; Jain, M.K.; Pandey, R.P. Development of modified SMA based MSCS-CN model for Runoff Estimation Water. Resour. Manag. 2015, 29, 4111-4127.

48. Verma, S.; Mishra, S.K.; Singh, A.; Singh, P.K.; Verma, R.K. An enhanced SMA based SCS-CN inspired model for watershed runoff prediction. Environ. Earth Sci. 2017, 76. [CrossRef]

49. Verma, S.; Singh, P.K.; Mishra, S.K.; Jain, S.K.; Berndtsson, R.; Singh, A.; Verma, R.K. Simplified SMA-inspired 1-parameter SCS-CN model for runoff estimation. Arab. J. Geosci. 2018, 11. [CrossRef]

50. Desmukh, D.S.; Chaube, U.C.; Hailu, A.E.; Gudeta, D.A.; Kassa, M.T. Estimation and comparison of curve numbers based on dynamic land use cover change, observed rainfall-runoff data and land slope. J. Hydrol. 2013, 492, 89-101. [CrossRef]

51. Huang, M.; Gallichand, J.; Wang, Z.; Goulet, M. A modification to the Soil Conservation Service curve number method for steep slopes in the Loess Plateau of China. Hydrol. Process. 2006, 20, 579-589. [CrossRef]

52. Plummer, A.; Woodward, D.E. The origin and Derivation of Ia/S in the Runoff Curve Number System. In Proceedings of the International Water Resources Engineering Conference, Memphis, TN, USA, 3-7 August 1998; Abt, S.R., Yoing-Pezeshk, J., Watson, C.C., Eds.; ASCE: Reston, VA, USA, 1998; pp. 1260-1265.

53. Fu, S.; Zhang, G.; Wang, N.; Luo, L. Initial abstraction ratio in the SCS-CN method in the Loess Plateau of China. Trans. ASABE 2011, 54, 163-169. [CrossRef]

54. Fan, F.; Deng, Y.; Hu, X.; Weng, Q. Estimating Composite Curve Number Using an Improved SCS-CN Method with Remotely Sensed Variables in Guangzhou, China. Remote Sens. 2013, 5, 1425-1438. [CrossRef]

55. Reistetter, J.A.; Russell, M. High-resolution land cover datasets, composite curve numbers, and storm water retention in the Tampa Bay, FL region. Appl. Geogr. 2011, 31, 740-747. [CrossRef]

56. Mockus, V. Design Hydrographs. In National Engineering Handbook; Section 4, Hydrology; McKeever, V., Owen, W., Rallison, R., Eds.; Soil Conservation Service: Washington, DC, USA, 1972.

57. Cazier, D.J.; Hawkins, R.H. Regional application of the curve number method. Water Today and Tomorrow. In Proceedings of the ASCE, Irrigation and Drainage Division Special Conference, Flagstaff, AZ, USA, 24-26 July 1984; Replogle, J.A., Ed.; ASCE: New York, USA, 1984.

58. Mishra, S.K.; Singh, V.P. Another look at SCS-CN method. J. Hydrol. Eng. 1999, 4, 257-264. [CrossRef]

59. Hawkins, R.H.; Khojeini, A.V. Initial Abstraction and Loss in the Curve Number Method Hydrol; Arizona-Nevada Academy of Science. Water Resour. Ariz. Southwest 2000, 30, 29-35.

60. Jiang, R. Investigation of Runoff Curve Number Initial Abstraction Ratio. Master's Thesis, The University of Arizona, Tucson, AZ, USA, 2001.

61. Lim, K.J.; Engel, B.A.; Muthukrishnan, S.; Harbor, J. Effects of initial abstraction and urbanization of estimated runoff using CN technology. J. Am. Water Resour. Assoc. 2006, 42, 629-643. [CrossRef] 
62. Baltas, E.A.; Dervos, N.A.; Mimikou, M.A. Technical Note: Determination of the SCS initial abstraction ratio in an experimental watershed in Greece. Hydrol. Earth Sys. Sci. 2007, 11, 1825-1829. [CrossRef]

63. Xiao, B.; Wang, Q.H.; Fan, J.; Han, F.P.; Dai, Q.H. Application of the SCS-CN model to runoff estimation on a small watershed with high spatial heterogeneity. Pedosphere 2011, 21, 738-749. [CrossRef]

64. Yuan, Y.; Nie, W.; McCutcheon, S.C.; Taguas, E. Initial abstraction and curve numbers for semiarid watersheds in Southeastern Arizona. Hydrol. Process. 2014, 28, 774-783. [CrossRef]

65. Janeček, M.; Dostál, T.; Dufková, J.K.; Dumbrovský, M.; Hůla, J.; Kadlec, V.; Konečná, J.; Kovář, P.; Krása, J.; Kubátová, E.; et al. Ochrana zemědělské půdy před erozí; Czech University of Life Sciences: Prague, Czech Republic, 2012; p. 113.

66. Caletka, M.; Honek, D. Improving direct runoff estimations through modifying SCS-CN initial abstraction ratio in a catchment prone to flash floods. In Proceedings of the International Multidisciplinary Scientific GeoConference Surveying Geology and Mining Ecology Management, lbena, Bulgaria, 28 June-7 July 2019; pp. 281-288.

67. Caletka, M.; Michalková, M.Š. Determination of SCS-CN initial Abstraction ratio in a chatchment prone to flash floods. Pollack Per. 2020, 15, 112-123.

68. Karabová, B. Testovanie možnosti regionalizácie vybraných parametrov metódy SCS-CN—Oblast nížin Slovenska. Acta Hydrol. Slovaca 2013, 15, 194-203.

69. Kohnová, S.; Karabová, B.; Hlavčová, K. On the possibilities of watershed parametrization of extreme flow estimation on ungauged basins. In Proceedings of the Congress in Flood Risk and Precipitation in Catchments and Cities, Prague, Czech Republic, 22 June-2 July 2015; Chen, Y., Estupina, V.B., Schumann, A., Aksoy, H., Bloschl, G., Kooy, M., Rogger, M., Toth, E., Eds.; Copernicus GmbH: Göttingen, Germany, 2015; pp. 171-175.

70. Kohnová, S.; Rutkowska, A.; Banasik, K.; Hlavčová, K. The L-moment based regional approach to curve numbers for Slovak and Polish Carpathian catchments. J. Hydrol. Hydromech. 2020, 68, 1-10. [CrossRef]

71. Daňhelka, J.; Kubát, J. Vyhodnocení Povodní v Červnu a Červenci 2009 (Assessment of Floods in June and July 2009 in the Czech Republic); Ministry of Environment, CHMI: Prague, Czech Republic, 2009; p. 165.

72. Šunka, Z. Vyhodnocení Povodní v Květnu a Červnu 2010 (Assessment of Floods in May and June 2010); Ministry of Environment, TGM WRI: Prague, Czech Republic, 2010; p. 172.

73. Honek, D.; Michalková, M.Š.; Smetanová, A.; Sočuvka, V.; Velísková, Y.; Karásek, P.; Konečná, J.; Némethová, Z.; Danáčová, M. Estimating sedimentation rates in small reservoirs-Suitable approaches for local municipalities in central Europe. J. Environ. Manag. 2020, 261. [CrossRef] [PubMed]

74. Goovaerts, P. Geostatistical approaches for incorporating elevation into the spatial interpolation of rainfall. J. Hydrol. 2000, 228, 113-129. [CrossRef]

75. Yang, K.; Cao, S.; Liu, X. Flow resistance and its precipitation methods in compound channels. Acta Mech. Sin. 2007, 23, 23-31. [CrossRef]

76. Pham, D.T.; Dimov, S.S.; Nguyen, C.D. Selection of K in K-means clustering. J. Mech. Eng. Sci. 2005, 219, 103-119. [CrossRef]

77. Dingman, S.L. Physical Hydrology, 2nd ed.; Macmillan Press Limited: New York, NY, USA, 2002; p. 646.

78. Konečná, J.; Karásek, P.; Beitlerová, H.; Fučík, P.; Kapička, J.; Podhrázská, J.; Kvítek, T. Using WaTEM/SEDEM and HEC-HMS episodic models for the simulation of episodic hydrological and erosion events in a small agricultural catchment. Soil Water Res. 2019, 15, 18-29. [CrossRef]

79. Muche, M.E.; Hutchinson, S.L.; Hutchinson, J.M.S.; Johnston, J.M. Phenology-adjusted dynamic curve number for improved hydrologic modelling. J. Environ. Manag. 2019, 235, 403-413. [CrossRef]

(C) 2020 by the authors. Licensee MDPI, Basel, Switzerland. This article is an open access article distributed under the terms and conditions of the Creative Commons Attribution (CC BY) license (http://creativecommons.org/licenses/by/4.0/). 